Review Article

\title{
Catalytic Synthesis of the Biofuel 5-Ethoxymethylfurfural (EMF) from Biomass Sugars
}

\author{
Dayong Yu $\left(\mathbb{D},{ }^{1,2}\right.$ Xiaofang Liu $\mathbb{D},{ }^{1}$ Jingjing Jiang $\left(\mathbb{D},{ }^{3}\right.$ Yixuan Liu $\left(\mathbb{D},{ }^{2}\right.$ Jinyu Tan $\left(\mathbb{D},{ }^{2}\right.$ \\ and $\mathrm{Hu} \mathrm{Li}$ iD $^{2}$ \\ ${ }^{1}$ Guizhou Provincial Key Laboratory for Rare Animal and Economic Insects of the Mountainous Region, \\ College of Biology and Environmental Engineering, Guiyang University, Guiyang 550005, China \\ ${ }^{2}$ State Key Laboratory Breeding Base of Green Pesticide \& Agricultural Bioengineering, \\ Key Laboratory of Green Pesticide \& Agricultural Bioengineering, Ministry of Education, \\ State-Local Joint Laboratory for Comprehensive Utilization of Biomass, Center for Research \& Development of Fine Chemicals, \\ Guizhou University, Guiyang, Guizhou 550025, China \\ ${ }^{3}$ School of Perfume and Aroma Technology, Shanghai Institute of Technology, Shanghai 200235, China
}

Correspondence should be addressed to Xiaofang Liu; liuxfzap@163.com and Hu Li; hli13@gzu.edu.cn

Received 25 June 2021; Revised 12 October 2021; Accepted 13 October 2021; Published 1 November 2021

Academic Editor: Antonio De Lucas Consuegra

Copyright (c) 2021 Dayong Yu et al. This is an open access article distributed under the Creative Commons Attribution License, which permits unrestricted use, distribution, and reproduction in any medium, provided the original work is properly cited.

\begin{abstract}
A new generation of bioplatform molecule 5-ethoxymethylfurfural (EMF) has excellent energy density and combustion performance, which makes it a potential fuel additive. This article reviews the factors that affect the production of EMF from different feedstocks, including platform compounds, monosaccharides, polysaccharides, and raw lignocellulosic biomass. Focus is placed on discussing the catalytic efficiency with pros and cons of different acid catalysts, including homogeneous catalysts (i.e., liquid acids and metal salts), heterogeneous catalysts (i.e., zeolites, heteropolyacid-based hybrids, and $\mathrm{SO}_{3} \mathrm{H}$-based catalysts), ionic liquids, mixed acid catalysts, and deep eutectic solvents (DESs). Except for the commonly used ethanol solvent, this review also summarizes the influence of the cosolvent system (e.g., ethanol/dimethylsulfoxide (DMSO), ethanol/tetrahydrofuran (THF), and ethanol $/ \gamma$-valerolactone (GVL)) on the EMF yield.
\end{abstract}

\section{Introduction}

The current production of fuels and chemicals is mainly based on nonrenewable fossil resources, such as coal and petroleum. With the increasing depletion of nonrenewable energy and the growing demand for energy by human beings, it is an urgent priority task to develop and utilize green and renewable energy $[1,2]$. Biomass is a new kind of sustainable resource on the earth that can replace fossil resources to obtain fuel and chemicals [3-6]. Meanwhile, it is widespread, abundant, diverse, and inexpensive [7]. To propose the development of a biorefinery plant, 12 platform chemicals derived from biomass substrates have been delimited by the US Department of Energy [8], such as hexoses, pentoses [9], 5-hydroxymethylfurfural (HMF) [10], EMF [11], levulinic acid (LA) [12], and ethyl levulinate (EL)
[13]. In order to obtain biofuels from carbohydrates, researchers have developed many methods, such as thermochemical treatment, enzymatic catalysis, and chemical catalysis [14-16].

Among these biofuels, EMF shows excellent physical and chemical properties and is considered as a prospective fuel additive and transportation fuel [17]. The high boiling point of $\operatorname{EMF}\left(235^{\circ} \mathrm{C}\right)$ is comparable to that of petrol $\left(30-220^{\circ} \mathrm{C}\right)$, and its energy density $(30.3 \mathrm{MJ} / \mathrm{L})$ is significantly higher than that of ethanol $(23.5 \mathrm{MJ} / \mathrm{L})$ and proximate to that of diesel fuel $(33.6 \mathrm{MJ} / \mathrm{L})$ and regular petrol $(31.3 \mathrm{MJ} / \mathrm{L})[18,19]$. EMF has a high cetane number and superior oxidation stability, because of which it can significantly reduce the emission of harmful particles and sulfides such as $\mathrm{NO}_{\mathrm{x}}, \mathrm{SO}_{2}, \mathrm{CO}_{2}$, and $\mathrm{CH}_{4}$ [20]. 17wt\% EMF was added to commercial gasoline. This mixed diesel was used to test engine performance and 
showed good results with a $16 \%$ reduction in soot [21]. In addition, EMF can also be used as a reaction substrate for the synthesis of other industrially significant chemicals. EMF can synthesise 5-ethoxymethylfurfuryl alcohol, dimethyltetrahydrofuran, and 2,5-diethoxymethylfuran through a onestep or multistep hydrogenation reaction $[22,23]$. EMF can also be converted into cyclopentenone in a stereoselective way via the Piancatelli rearrangement reaction [24]. In the process of EMF synthesis reaction, the ring is usually further opened to generate the high value-added chemical EL [25]. Meanwhile, EMF can also be used as an additive for beer flavor and aroma [26].

Currently, the mainstream synthesis path of EMF is the use of an acid catalyst to promote biomass sugars (e.g., fructose, glucose, and inulin) being converted via cascade reactions such as hydrolysis, dehydration, and etherification under the ethanol system. Although the feedstocks are different, the most classic method is the utilization of fructose as the raw material to synthesise EMF. The involved reaction mechanism is shown in Scheme 1. It is worth noting that EMF can also be obtained directly by etherification of HMF. Meanwhile, changing the solvent system to obtain a high yield of EMF has also been explored in the past few years. This paper reviewed recent research on the use of biomass sugar conversion to synthesise EMF and focused on the effects of different feedstocks, catalysts, and solvent systems on the yield of EMF.

\section{The Synthesis of EMF}

In the process of synthesising EMF, catalysts, raw materials, and solvents are the key components in the reaction system. Acids are important and regular catalysts to catalyze biomass conversion into platform chemicals and advanced biofuels. Therefore, EMF can be produced by the etherification of $\mathrm{HMF}$ in an ethanol medium with an acid catalyst as motivation. Scheme 2 shows the reaction pathways of EMF synthesis from ethanolysis of carbohydrates (e.g., fructose, glucose, sucrose, and cellulose).

With a "one-pot" method, direct assembly of EMF from disaccharides, polysaccharides, and biomass sugars shows obvious advantages in the economy and less energy intensity. This method can reduce the cost and steps of intermediate separation and purification [27-29]. But, it always has a relatively lower yield of EMF from these complex carbohydrates, compared with fructose, HMF, 5chloromethylfurfural (CMF), and 5-bromomethylfurfural (BMF) [29-33]. Also, EMF can be prepared by nucleophilic substitution of BMF and CMF $[34,35]$ or etherification of HMF in ethanol [36, 37]. Among the three chemical platform molecules, HMF is the most commonly used one for the preparation of EMF. Transformation of disaccharides, polysaccharides, and biomass sugars into platform compounds (e.g., HMF, CMF, and BMF) typically undergoes hydrolysis, isomerization, esterification, chlorination, and etherification. The lengthy chemical reaction process will increase energy consumption and result in more byproducts, which is the cause of the low yield of EMF. For example, cellulose as a feedstock undergoes at least four steps to synthesise EMF. First, cellulose is hydrolyzed to glucose, and then, fructose comes from glucose isomerization, followed by dehydration of three $\mathrm{H}_{2} \mathrm{O}$ molecules to give HMF. Finally, EMF is synthesised by etherification of HMF $[38,39]$. Because of the multiple steps required for the synthesis of EMF, side reactions are more likely to occur, which convert intermediate products into other byproducts or humins.

\section{Feedstocks}

Currently, the feedstocks for the formation of EMF are mainly divided into four types based on the difference in reaction pathways. (i) EMF is prepared by directly etherifying platform compounds, such as $\mathrm{HMF}, \mathrm{BMF}$, and $\mathrm{CMF}$ [29-32]. (ii) Monosaccharides such as fructose and glucose are dehydrated to HMF followed by etherification to synthesise EMF under acidic conditions [40, 41]. (iii) Disaccharides and polysaccharides such as starch, sucrose, cellobiose, inulin, and cellulose are used to produce EMF via the steps of hydrolysis, isomerism, dehydration, and etherification [29, 41-44]. (iv) Lignocellulosic biomass such as corn stover, cassava, and sugarcane bagasse is directly converted to EMF through a "one-pot" method $[45,46]$. The results of different feedstocks used to produce EMF are summarized in Table 1.

3.1. Platform Molecules. The platform molecules such as HMF, BMF, and CMF all have a furan ring and an aldehyde group, which can be used to transform and prepare a variety of biofuels and fine chemicals. HMF can usually be directly etherified in an ethanol medium in the presence of an acid catalyst to obtain EMF. Also, HMF is composed of a furan ring, an aldehyde group, and a hydroxymethyl group, which makes its chemical properties active. Due to the excellent characteristics of HMF, many studies have proved that a high EMF yield (ca. 90\%) can be obtained from it. Yang et al. [11] explored a niobium-molybdate solid acid that was recyclable and had a multilayer structure. The authors utilized this catalyst to promote HMF being transformed into EMF at $100^{\circ} \mathrm{C}$ for $12 \mathrm{~h}$. Surprisingly, the highest yield of EMF was over 99\%. Another high yield of EMF was $92.9 \%$ from $\mathrm{HMF}$ at $100^{\circ} \mathrm{C}$ for $5 \mathrm{~h}$ with $\mathrm{AlCl}_{3}$ in ethanol [47]. However, the high cost of HMF limits the feasibility of its industrial application.

3.2. Monosaccharides. Fructose and glucose are the main monosaccharide raw materials for the formation of EMF. Generally, the yield of EMF is higher when fructose is used as raw material. Karnjanakom et al. [27] used $\mathrm{Zn}-\mathrm{S}-\mathrm{C}$ to transform fructose into EMF (95.5\% yield) in an ethanol solvent with tetrahydrofuran (THF) as a cosolvent under the optimal conditions $\left(98^{\circ} \mathrm{C}, 47 \mathrm{~min}\right)$. However, glucose as a substrate always leads to a low yield of EMF (10\%-40\%) $[44,47-49]$ due to the effect of the speed limit of glucose being isomerized into fructose. Xin et al. [48] used a composite catalyst consisting of PTSA-POM and $\mathrm{AlCl}_{3} \cdot 6 \mathrm{H}_{2} \mathrm{O}$ to catalyze glucose into EMF, and the yield was only $30.6 \%$. 


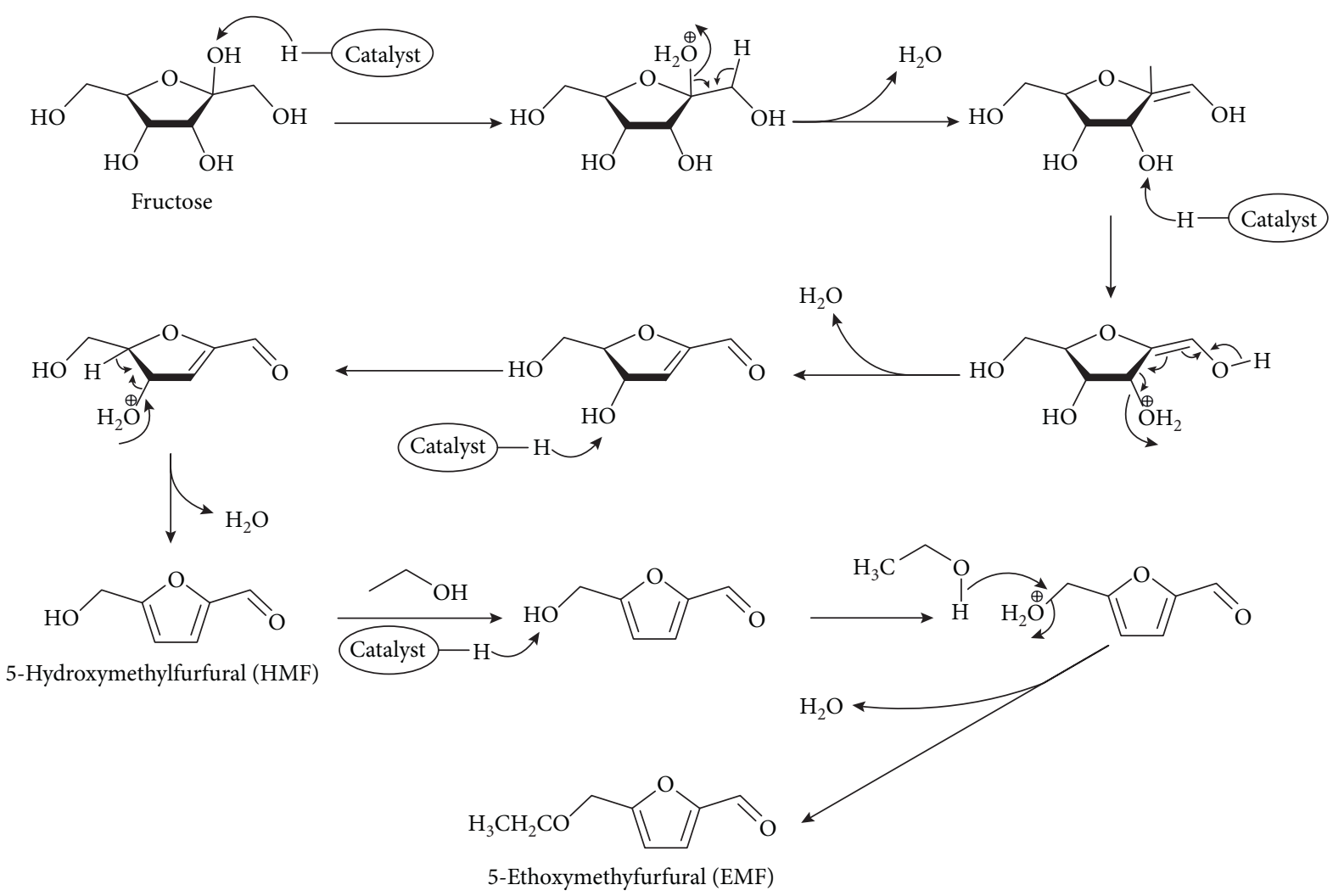

Scheme 1: The reaction mechanism involved in the conversion of fructose to EMF.

3.3. Di- and Polysaccharides. When using biomass sugars such as sucrose, inulin, and starch as feedstocks to produce EMF, a higher content of fructose molecules in the internal biomass sugars is positively correlated with the yield of EMF. One molecule of inulin is composed of one unit of glucose and 1-59 units of fructose, and the obtained yield of EMF is between 55\% and $80 \%$ [49-52]. Furthermore, one molecule of sucrose comprises one unit of glucose and one unit of fructose, with a fructose content of $50 \%$ that is lower than inulin, and its yield of EMF is between $10 \%$ and $45 \%$ [53-56]. The hydrolysate of starch $[28,50]$, cellobiose $[50,51,56]$, and cellulose $[51,52]$ is glucose, so the EMF yield of these substrates is generally low. From Scheme 2, we can know that glucose-based carbohydrates (starch, cellobiose, and cellulose) have two ways to convert glucose into EMF. These carbohydrates are initially hydrolyzed into glucose. Then, two possible ways may be involved: (i) fructose prepared by isomerizing glucose is dehydrated to EMF and (ii) glucose is esterified to ethyl-D-glucopyranoside (EDGP) in an ethanol medium in the presence of Brønsted acid followed by isomerization to ethyl-D-fructofuranoside (EDFF) and final dehydration to produce EMF.

3.4. Lignocellulosic Biomass. Lignocellulosic biomass has widespread, abundant, and inexpensive advantages. It is, therefore, regarded as an appealing and promising alternative to produce EMF [16]. At present, the raw materials used to directly prepare EMF from waste biomass are mainly sugarcane bagasse, corn stover, and cassava. Dutta et al. [53] used $\mathrm{Zr}(\mathrm{O}) \mathrm{Cl}_{2}-\mathrm{CrCl}_{3}$ metal chloride catalysts to produce EMF (21.6\% yield) from sugarcane bagasse in ethanol-[BMIM]Cl at $120^{\circ} \mathrm{C}$ for $15 \mathrm{~h}$. A relatively satisfactory EMF yield (23.9\%) was detected from corn stover at $210^{\circ} \mathrm{C}$ for $125 \mathrm{~min}$ by using a mixed acid catalyst $(0.1 \%$ $\mathrm{H}_{2} \mathrm{SO}_{4}$ and zeolite USY) [45]. In addition, Tan et al. [46] selected some sulfates such as $\mathrm{Al}_{2}\left(\mathrm{SO}_{4}\right)_{3}, \mathrm{Fe}_{2}\left(\mathrm{SO}_{4}\right)_{3}, \mathrm{NaHSO}_{4}, \mathrm{MgSO}_{4}$, $\mathrm{ZnSO}_{4}$, and $\mathrm{NiSO}_{4}$ to catalyze the synthesis of EMF from cassava, and the obtained yield of EMF was $0.36 \%, 3.01 \%$, $4.43 \%, 0.09 \%, 3.25 \%$, and $11.04 \%$, respectively. In general, when using lignocellulosic biomass as the feedstock, the yield of EMF is very low, possibly attributed to the complex structure of lignocellulosic biomass, which reduces the catalyst accessibility. Therefore, researchers should focus on the recycling of lignocellulosic biomass and explore more effective catalysts.

\section{Catalysts}

A catalyst is an indispensable and significant component in the catalytic system. The preparation of EMF with carbohydrates as raw materials usually needs to be carried out under the action of acid catalysts. Acid catalysts can stimulate some necessary reactions such as hydrolysis of disaccharides and polysaccharides to fructose and glucose, glucose isomerization, fructose dehydration, and HMF etherification. Furthermore, it is indicated that the ratio of Lewis acid and Brønsted acid can influence the selectivity of EMF, and Brønsted acid plays a very imperative part in catalyzing the reaction of carbohydrates and HMF to prepare EMF [28, 48, 57, 58]. Nowadays, both homogeneous catalysts and heterogeneous catalysts have been developed to be widely used in this reaction. 


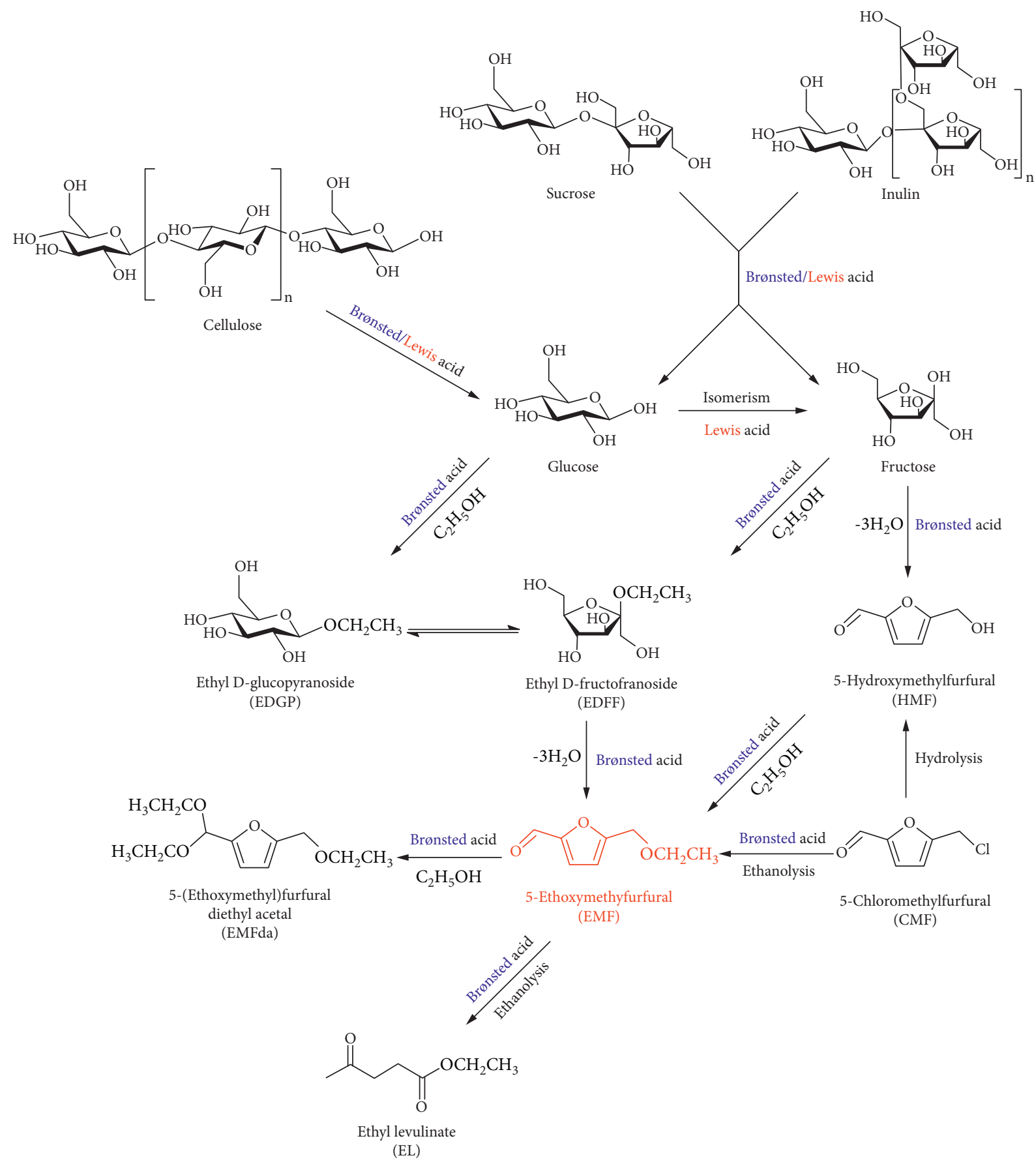

Scheme 2: The reaction paths of synthesising EMF from carbohydrates.

4.1. Homogeneous Catalysts. Homogeneous acid catalysts have excellent catalytic performance in etherification, dehydration, and other reactions and are superior choices for catalytic synthesis of EMF. The synthesis of EMF by homogeneous catalysts from different carbohydrates is summarized in Table 2, including liquid acids and metal salts.

4.1.1. Liquid Acid Catalysts. Liquid acids such as $\mathrm{H}_{2} \mathrm{SO}_{4}$, $\mathrm{HCl}$, and $\mathrm{H}_{3} \mathrm{PO}_{4}$ are the typical homogeneous catalysts. Their excellent catalytic performance is due to their uniform distribution in the solvent, which can increase the accessibility of the catalyst and substrate. $\mathrm{H}_{2} \mathrm{SO}_{4}$ is most frequently used in the process of biomass alcoholysis. Balakrishnan et al. [21] used a low concentration of $\mathrm{H}_{2} \mathrm{SO}_{4}(10 \mathrm{~mol} \%)$ to obtain EMF from fructose with an acceptable yield (70\%). When replacing fructose with HMF, they obtained a higher EMF yield ( $81 \%)$ by $\mathrm{H}_{2} \mathrm{SO}_{4}(5 \mathrm{~mol} \%)$ in ethanol. Another high yield of EMF was also observed at $79.8 \%$ for $5 \mathrm{~mol} \%$ $\mathrm{H}_{2} \mathrm{SO}_{4}$ with $100 \%$ conversion of HMF [59]. Although a higher EMF yield can be obtained when $\mathrm{H}_{2} \mathrm{SO}_{4}$ is used as a catalyst, there are some obstructions: (i) High 
TABLE 1: Catalytic preparation of EMF from various feedstocks.

\begin{tabular}{|c|c|c|c|c|c|c|}
\hline Entry & Feedstock & Catalyst & Solvent & Reaction condition & Yield (\%) & Ref. \\
\hline 1 & Fructose & $\mathrm{H}_{1.15} \mathrm{Nb}_{1.15} \mathrm{Mo}_{0.85} \mathrm{O}_{6}$ & Ethanol & $100^{\circ} \mathrm{C}, 1 \mathrm{~h}$ & 67 & {$[11]$} \\
\hline 2 & HMF & $\mathrm{H}_{1.15} \mathrm{Nb}_{1.15} \mathrm{Mo}_{0.85} \mathrm{O}_{6}$ & Ethanol & $100^{\circ} \mathrm{C}, 1 \mathrm{~h}$ & $>99$ & [11] \\
\hline 3 & HMF & $\mathrm{AlCl}_{3}$ & Ethanol & $100^{\circ} \mathrm{C}, 5 \mathrm{~h}$ & 92.9 & [47] \\
\hline 4 & Glucose & $\mathrm{AlCl}_{3}$ & Ethanol & $100^{\circ} \mathrm{C}, 11 \mathrm{~h}$ & 38.4 & [47] \\
\hline 5 & Fructose & $\mathrm{AlCl}_{3}$ & Ethanol & $100^{\circ} \mathrm{C}, 11 \mathrm{~h}$ & 71.2 & [47] \\
\hline 6 & Fructose & $\mathrm{Zn}-\mathrm{S}-\mathrm{C}$ & Ethanol/THF & $98^{\circ} \mathrm{C}, 42 \mathrm{~min}$ & 95.5 & [27] \\
\hline 7 & Sucrose & $\mathrm{Zn}-\mathrm{S}-\mathrm{C}$ & Ethanol/THF & $98^{\circ} \mathrm{C}, 42 \mathrm{~min}$ & 93.5 & [27] \\
\hline 8 & Glucose & $\mathrm{Zn}-\mathrm{S}-\mathrm{C}$ & Ethanol/THF & $98^{\circ} \mathrm{C}, 42 \mathrm{~min}$ & 80.9 & [27] \\
\hline 9 & Inulin & $\mathrm{Zn}-\mathrm{S}-\mathrm{C}$ & Ethanol/THF & $98^{\circ} \mathrm{C}, 42 \mathrm{~min}$ & 64.8 & [27] \\
\hline 10 & Inulin & GO & Ethanol/DMSO & $130^{\circ} \mathrm{C}, 24 \mathrm{~h}$ & 71 & [44] \\
\hline 11 & Fructose & GO & Ethanol/DMSO & $130^{\circ} \mathrm{C}, 24 \mathrm{~h}$ & 3 & [44] \\
\hline 12 & Sucrose & GO & Ethanol/DMSO & $130^{\circ} \mathrm{C}, 24 \mathrm{~h}$ & 66 & [44] \\
\hline 13 & Glucose & $\mathrm{GO}$ & Ethanol/DMSO & $130^{\circ} \mathrm{C}, 24 \mathrm{~h}$ & 34 & [44] \\
\hline 14 & Glucose & $\mathrm{PTSA}-\mathrm{POM} / \mathrm{AlCl}_{3} \cdot 6 \mathrm{H}_{2} \mathrm{O}$ & Ethanol $/ \mathrm{H}_{2} \mathrm{O}$ & $150^{\circ} \mathrm{C}, 30 \mathrm{~min}$ & 30.6 & [48] \\
\hline 15 & Glucose & PU-Cat & Ethanol/1, 4-dioxane & $140^{\circ} \mathrm{C}, 4 \mathrm{~h}$ & 9.2 & [49] \\
\hline 16 & Sucrose & PU-Cat & Ethanol/1, 4-dioxane & $140^{\circ} \mathrm{C}, 4 \mathrm{~h}$ & 31.3 & [49] \\
\hline 17 & Inulin & PU-Cat & Ethanol/1, 4-dioxane & $140^{\circ} \mathrm{C}, 4 \mathrm{~h}$ & 58.1 & [49] \\
\hline 18 & Starch & $\mathrm{Al}_{2}\left(\mathrm{SO}_{4}\right)_{3} / \mathrm{H}_{3} \mathrm{PO}_{4}$ & Ethanol/DMSO & $170^{\circ} \mathrm{C}, 10 \mathrm{~h}$ & 34.3 & [28] \\
\hline 19 & Starch & BFC- 3 & Ethanol/THF & $100^{\circ} \mathrm{C}, 12 \mathrm{~h}$ & 28.8 & [50] \\
\hline 20 & Cellobiose & BFC-3 & Ethanol/THF & $100^{\circ} \mathrm{C}, 10 \mathrm{~h}$ & 37.1 & {$[50]$} \\
\hline 21 & Cellobiose & PSDVB- $\mathrm{SO}_{3} \mathrm{H}$ & Ethanol & $120^{\circ} \mathrm{C}, 2 \mathrm{~h}$ & Trace & [51] \\
\hline 22 & Cellulose & $\mathrm{H}_{2} \mathrm{SO}_{4}$ & Ethanol & $200^{\circ} \mathrm{C}, 1.5 \mathrm{~h}$ & 3.05 & [52] \\
\hline 23 & Corn stover & $\mathrm{H}_{2} \mathrm{SO}_{4}(0.1$ wt $\%) / \mathrm{USY}$ & Ethanol & $210^{\circ} \mathrm{C}, 2 \mathrm{~h}$ & 23.9 & [45] \\
\hline 24 & Cassava & $\mathrm{NiSO}_{4}$ & Ethanol & $200^{\circ} \mathrm{C}, 6 \mathrm{~h}$ & 11.04 & [46] \\
\hline 25 & Cassava & $\mathrm{NaHSO}_{4}$ & Ethanol & $200^{\circ} \mathrm{C}, 6 \mathrm{~h}$ & 4.43 & [46] \\
\hline 26 & Bagasse & $\mathrm{Zr}(\mathrm{O}) \mathrm{Cl}_{2} / \mathrm{CrCl}_{3}$ & Ethanol/[BMIM]Cl & $120^{\circ} \mathrm{C}, 15 \mathrm{~h}$ & 21.6 & [53] \\
\hline
\end{tabular}

TABLE 2: Various homogeneous catalysts used for EMF synthesis.

\begin{tabular}{|c|c|c|c|c|c|c|}
\hline Entry & Catalyst & Feedstock & Solvent & Reaction condition & Yield (\%) & Ref. \\
\hline 1 & $5 \mathrm{~mol}^{2} \mathrm{H}_{2} \mathrm{SO}_{4}$ & HMF & Ethanol & $75^{\circ} \mathrm{C}, 24 \mathrm{~h}$ & 81 & {$[21]$} \\
\hline 2 & $10 \mathrm{~mol}^{2} \mathrm{H}_{2} \mathrm{SO}_{4}$ & Fructose & Ethanol & $100^{\circ} \mathrm{C}, 24 \mathrm{~h}$ & 70 & [21] \\
\hline 3 & $\mathrm{H}_{2} \mathrm{SO}_{4}$ & HMF & Ethanol & $70^{\circ} \mathrm{C}, 18 \mathrm{~h}$ & 79.8 & [59] \\
\hline 4 & $\mathrm{FeCl}_{3}$ & Fructose & Ethanol/[Bmim $] \mathrm{Cl}$ & $120^{\circ} \mathrm{C}, 10 \mathrm{~h}$ & 39.9 & [60] \\
\hline 5 & $\mathrm{AlCl}_{3} \cdot 6 \mathrm{H}_{2} \mathrm{O}$ & HMF & Ethanol $/ \mathrm{H}_{2} \mathrm{O}$ & $160^{\circ} \mathrm{C}, 15 \mathrm{~min}$ & 70 & [61] \\
\hline 6 & $\mathrm{AlCl}_{3} \cdot 6 \mathrm{H}_{2} \mathrm{O}$ & Fructose & Ethanol $/ \mathrm{H}_{2} \mathrm{O}$ & $160^{\circ} \mathrm{C}, 15 \mathrm{~min}$ & 46 & [61] \\
\hline 7 & $\mathrm{AlCl}_{3} \cdot 6 \mathrm{H}_{2} \mathrm{O}$ & Glucose & Ethanol $/ \mathrm{H}_{2} \mathrm{O}$ & $160^{\circ} \mathrm{C}, 15 \mathrm{~min}$ & 33 & [61] \\
\hline 8 & $\mathrm{AlCl}_{3} \cdot 6 \mathrm{H}_{2} \mathrm{O}$ & Ethyl glucoside & Ethanol/ $\mathrm{H}_{2} \mathrm{O}$ & $160^{\circ} \mathrm{C}, 15 \mathrm{~min}$ & 27 & [61] \\
\hline 9 & $\mathrm{CuCl}_{2} \cdot 2 \mathrm{H}_{2} \mathrm{O}$ & Fructose & Ethanol & $100^{\circ} \mathrm{C}, 12 \mathrm{~h}$ & 12 & [62] \\
\hline 10 & $\mathrm{NiCl}_{2} \cdot 6 \mathrm{H}_{2} \mathrm{O}$ & Fructose & Ethanol & $100^{\circ} \mathrm{C}, 12 \mathrm{~h}$ & 5 & [62] \\
\hline 11 & $\mathrm{SnCl}_{4} \cdot 5 \mathrm{H}_{2} \mathrm{O}$ & Fructose & Ethanol & $100^{\circ} \mathrm{C}, 12 \mathrm{~h}$ & 23 & {$[62]$} \\
\hline 12 & $\mathrm{FeCl}_{3}$ & Fructose & Ethanol & $100^{\circ} \mathrm{C}, 12 \mathrm{~h}$ & 28 & [62] \\
\hline 13 & $\mathrm{CrCl}_{3} \cdot 6 \mathrm{H}_{2} \mathrm{O}$ & Fructose & Ethanol & $100^{\circ} \mathrm{C}, 12 \mathrm{~h}$ & 33 & {$[62]$} \\
\hline 14 & $\mathrm{AlCl}_{3}$ & Fructose & Ethanol & $140^{\circ} \mathrm{C}, 10 \mathrm{~h}$ & 45 & [63] \\
\hline 15 & $\mathrm{CuCl}_{2}$ & Fructose & Ethanol & $140^{\circ} \mathrm{C}, 10 \mathrm{~h}$ & 34.7 & [63] \\
\hline 16 & $\mathrm{FeCl}_{3}$ & Fructose & Ethanol & $140^{\circ} \mathrm{C}, 10 \mathrm{~h}$ & 24.7 & [63] \\
\hline 17 & $\mathrm{CrCl}_{3}$ & Fructose & Ethanol & $140^{\circ} \mathrm{C}, 10 \mathrm{~h}$ & 36.9 & [63] \\
\hline 18 & $\mathrm{Al}_{2}\left(\mathrm{SO}_{4}\right)_{3}$ & Fructose & Ethanol & $140^{\circ} \mathrm{C}, 10 \mathrm{~h}$ & 20.8 & [63] \\
\hline 19 & $\mathrm{CuSO}_{4}$ & Fructose & Ethanol & $140^{\circ} \mathrm{C}, 10 \mathrm{~h}$ & 14.7 & [63] \\
\hline 20 & $\mathrm{Fe}_{2}\left(\mathrm{SO}_{4}\right)_{3}$ & Fructose & Ethanol & $140^{\circ} \mathrm{C}, 10 \mathrm{~h}$ & 18.2 & [63] \\
\hline 21 & $\mathrm{Cr}_{2}\left(\mathrm{SO}_{4}\right)_{3}$ & Fructose & Ethanol & $140^{\circ} \mathrm{C}, 10 \mathrm{~h}$ & 0.5 & [63] \\
\hline 22 & $\mathrm{AlCl}_{3} \cdot 6 \mathrm{H}_{2} \mathrm{O}$ & Fructose & Ethanol & $110^{\circ} \mathrm{C}, 5 \mathrm{~h}$ & 25.8 & [64] \\
\hline 23 & $\mathrm{AlCl}_{3} \cdot 6 \mathrm{H}_{2} \mathrm{O} / \mathrm{BF}_{3} \cdot(\mathrm{Et})_{2} \mathrm{O}$ & Fructose & Ethanol & $110^{\circ} \mathrm{C}, 3 \mathrm{~h}$ & 55 & [64] \\
\hline 24 & $\mathrm{AlCl}_{3} \cdot 6 \mathrm{H}_{2} \mathrm{O} / \mathrm{B}(\mathrm{OH})_{3}$ & Fructose & Ethanol & $110^{\circ} \mathrm{C}, 3 \mathrm{~h}$ & 22 & [64] \\
\hline 25 & $\mathrm{AlCl}_{3} \cdot 6 \mathrm{H}_{2} \mathrm{O} / \mathrm{NaF}$ & Fructose & Ethanol & $110^{\circ} \mathrm{C}, 3 \mathrm{~h}$ & 25.1 & [64] \\
\hline 26 & $\mathrm{AlCl}_{3} \cdot 6 \mathrm{H}_{2} \mathrm{O} / \mathrm{NaCl}$ & Fructose & Ethanol & $110^{\circ} \mathrm{C}, 3 \mathrm{~h}$ & 28.9 & [64] \\
\hline 27 & $\mathrm{AlCl}_{3} \cdot 6 \mathrm{H}_{2} \mathrm{O} / \mathrm{NaBr}$ & Fructose & Ethanol & $110^{\circ} \mathrm{C}, 3 \mathrm{~h}$ & 26.3 & {$[64]$} \\
\hline
\end{tabular}


concentrations of liquid acids will corrode the equipment. (ii) A low concentration of liquid acids requires harsh reaction conditions such as higher pressure and higher temperature. (iii) The product separation is a significant issue. (iv) Liquid acids will cause environmental pollution.

4.1.2. Metal Salt Catalysts. Metal salts exhibit excellent catalytic performance and low toxicity in catalytic chemical reactions. As Lewis acid catalysts, they have been widely used to catalyze the conversion of carbohydrates to EMF in recent years. A series of metal salts, mainly including metal chlorides and sulfates, have been investigated, such as $\mathrm{AlCl}_{3}, \mathrm{CuCl}_{2}, \mathrm{FeCl}_{3}, \mathrm{CrCl}_{3}, \mathrm{SnCl}_{4}, \mathrm{NiCl}_{2}, \mathrm{Al}_{2}\left(\mathrm{SO}_{4}\right)_{3}$, $\mathrm{CuSO}_{4}, \mathrm{Fe}_{2}\left(\mathrm{SO}_{4}\right)_{3}$, and $\mathrm{Cr}_{2}\left(\mathrm{SO}_{4}\right)_{3}$. A normal metal chloride $\left(\mathrm{FeCl}_{3}\right)$ was used to discuss the effects of different reaction temperatures and time on the yield of EMF in a cosolvent system (ethanol and ionic liquid $[\mathrm{Bmim}] \mathrm{Cl}$ ) by Zhou et al. [60]. When the temperature was raised from $80^{\circ} \mathrm{C}$ to $120^{\circ} \mathrm{C}$, the yield of EMF increased from $6.4 \%$ to $39.9 \%$, but there was still a problem of low yield. Yang et al. [61] utilized $\mathrm{AlCl}_{3} \cdot 6 \mathrm{H}_{2} \mathrm{O}$ as an efficient catalyst to obtain EMF from various carbohydrates (i.e., glucose, ethyl glucoside, fructose, and HMF) in an ethanol-water mixture at $160^{\circ} \mathrm{C}$ for $15 \mathrm{~min}$. Glucose, ethyl glucoside, and fructose gave a moderate EMF yield of 33\%, 27\%, and $46 \%$, respectively. However, a relatively high EMF yield (70\%) was detected from HMF. Another study showed a satisfactory EMF yield (92.9\%) from $\mathrm{HMF}$ by using $\mathrm{AlCl}_{3}$. Various metal chlorides (i.e., $\mathrm{CuCl}_{2} \cdot 2 \mathrm{H}_{2} \mathrm{O}, \mathrm{NiCl}_{2} \cdot 6 \mathrm{H}_{2} \mathrm{O}, \mathrm{SnCl}_{4} \cdot 5 \mathrm{H}_{2} \mathrm{O}, \mathrm{FeCl}_{3}$, and $\mathrm{CrCl}_{3} \cdot 6 \mathrm{H}_{2} \mathrm{O}$ ) were also investigated as catalysts to synthesise EMF, but all with low EMF yields [62]. According to the research of Yu et al. [63], except metal chlorides, metal sulfates were also used to synthesise EMF from fructose in an ethanol medium, but with a disappointing yield $(0.5 \%-$ $20.8 \%)$ that is even lower than that of metal chlorides. It can be found that $\mathrm{AlCl}_{3}$ obtained the highest yield of EMF (45\%), while $\mathrm{Fe}_{2}\left(\mathrm{SO}_{4}\right)_{3}$ produced the highest EL yield (56.8\%). These research studies indicate that $\mathrm{AlCl}_{3}$ can be a better option for metal salt catalysts in the synthesis of EMF from different carbohydrates. In an effort to improve the catalytic activity of $\mathrm{AlCl}_{3}$, a cocatalyst system was explored by Jia et al. [64] which consists of $\mathrm{AlCl}_{3} \cdot 6 \mathrm{H}_{2} \mathrm{O}$ and a cocatalyst (i.e., $\mathrm{BF}_{3} \cdot(\mathrm{Et})_{2} \mathrm{O}, \mathrm{B}(\mathrm{OH})_{3}, \mathrm{NaF}, \mathrm{NaCl}$, and $\mathrm{NaBr}$ ), and the molar ratio of $\mathrm{AlCl}_{3} \cdot 6 \mathrm{H}_{2} \mathrm{O} /$ cocatalyst was $1: 1$. When $\mathrm{B}(\mathrm{OH})_{3}$ and $\mathrm{NaF}$ were used as cocatalysts, the yield of EMF had a slight reduction to $22 \%$ and $25.1 \%$, respectively. On the other hand, $\mathrm{AlCl}_{3} \cdot 6 \mathrm{H}_{2} \mathrm{O}$ (25.8\%) with $\mathrm{BF}_{3}(\mathrm{Et})_{2} \mathrm{O}, \mathrm{NaCl}$, and $\mathrm{NaBr}$ as a cocatalysts could all improve the EMF yield; especially, $\mathrm{BF}_{3} \cdot(\mathrm{Et})_{2} \mathrm{O}$ had the highest EMF yield (55\%).

Currently, the use of homogeneous catalysts to prepare EMF has a relatively mature system and higher yields. However, due to a large number of byproducts from homogeneous acid catalysts, the corrosion of the equipment and the high requirements for reaction conditions have restricted their use in industry. Therefore, green, economical, and recyclable heterogeneous catalytic systems have great potential in this field $[27,55,65-68]$.
4.2. Heterogeneous Catalysts. Heterogeneous catalysts have been the focus of research in recent years, which have the advantages of being easily separated from the reaction system, not corroding equipment, superior recyclability, and excellent thermal stability [69]. In addition, heterogeneous catalysts can be modified in the process of preparation to obtain more excellent catalytic performance, such as adjustable Lewis acid sites and Brønsted acid sites or specific surface areas [67]. In the process of biomass ethanolysis to produce EMF, the main heterogeneous catalysts include zeolites, heteropolyacids-based hybrids, and sulfonic acidfunctionalized catalysts, which are summarized in Table 3.

4.2.1. Zeolite Catalysts. Zeolite is also known as a molecular sieve catalyst, which is either a natural or synthetic chemical substance with a network structure. With the development of ZSM-5 molecular sieves as a catalyst, such catalysts (e.g., MCM-41, SBA-15, and USY) have received widespread attention. In recent years, researchers have applied these catalysts for the synthesis of EMF [80].

Zeolites are solely used to catalyze a reaction, typically with poor catalytic performance. Therefore, zeolites can be modified to obtain high-efficiency catalysts with different specific surface areas, different acidity, and alkalinity. For instance, Liu et al. [70] successfully loaded different concentrations of $\mathrm{H}_{3} \mathrm{PW}_{12} \mathrm{O}_{40}$ (HPW) onto MCM-41. They found that the yield of EMF by MCM-41 was only at a very weak concentration (0.2\%). However, when the MCM-41 was loaded with $40 \mathrm{wt} \%$ of $\mathrm{H}_{3} \mathrm{PW}_{12} \mathrm{O}_{40}$, the achieved EMF yield was $83.4 \%$. The high yield of EMF achieved by MCM41-HPW loaded with 40 wt $\% \mathrm{H}_{3} \mathrm{PW}_{12} \mathrm{O}_{40}$ could be attributed to its strong acidity, with an $E i$ value of $667 \mathrm{mV}$. In addition, Che et al. [71] used MCM-41 nanospheres (M-Ns) and $\mathrm{H}_{4} \mathrm{SiW}_{12} \mathrm{O}_{40}$ ( $\mathrm{HSiW}$ ) to synthesise a mesoporous nanosphere catalyst (HSiW/M-Ns). They measured the acid strength of various acids, and the order was $\mathrm{HSiW} \approx \mathrm{H}_{3} \mathrm{PW}_{12} \mathrm{O}_{40} \quad(\mathrm{HPW})>\mathrm{H}_{2} \mathrm{SO}_{4}>\quad \mathrm{PTSA}>\mathrm{H}_{3} \mathrm{PO}_{4}$. Then, they used $20 \mathrm{wt} \% \sim 60 \mathrm{wt} \% \mathrm{HSiW} / \mathrm{M}-\mathrm{Ns}$ and these acids to transform HMF into EMF. The results show that the highest conversion of HMF (92\%) and selectivity of EMF $(84.1 \%)$ could be obtained by using $40 \mathrm{wt} \% \mathrm{HSiW} / \mathrm{M}-\mathrm{Ns}$. The conversion rate lower than that of HSiW/M-Ns by other acids indicated that tungstosilicate anion and acid strength could promote HMF conversion and increase EMF selectivity. Lanzafame et al. [81] synthesised a sequence of AlMCM-41 zeolites which had a mesoporous structure and different $\mathrm{Si} / \mathrm{Al}$ ratios, and $\mathrm{ZrO}_{2}$ introduced into the SBA-15, named Z-SBA-15, could both obtain higher EMF yields from HMF. This is because these catalysts had remarkable Lewis acid sites and $\mathrm{Al}^{3+}$ sites were isolated outside the framework. Through the sulfonation modification of SBA-15, the catalyst $\mathrm{Ar}-\mathrm{SO}_{3} \mathrm{H}-\mathrm{SBA}-15$ was prepared by Morales et al. [66] A maximum EMF yield (63.4\%) was obtained from fructose over $\mathrm{Ar}-\mathrm{SO}_{3} \mathrm{H}-\mathrm{SBA}-15$ at $116^{\circ} \mathrm{C}$ for $4 \mathrm{~h}$ in a cosolvent system with ethanol and DMSO. The excellent catalytic capability of Ar- $-\mathrm{SO}_{3} \mathrm{H}-\mathrm{SBA}-15$ was due to the combination of outstanding structural properties and the surface concentration of acid sites and strength. Zeolite USY was also used for EMF 
TABLE 3: Various heterogeneous catalysts used for EMF synthesis.

\begin{tabular}{|c|c|c|c|c|c|c|}
\hline Entry & Catalyst & Feedstock & Solvent & Reaction condition & Yield (\%) & Ref. \\
\hline 1 & MCM- 41 & HMF & Ethanol & $100^{\circ} \mathrm{C}, 12 \mathrm{~h}$ & 0.2 & {$[70]$} \\
\hline 2 & 10 wt.\% MCM-41-HPW & $\mathrm{HMF}$ & Ethanol & $100^{\circ} \mathrm{C}, 12 \mathrm{~h}$ & 25.8 & {$[70]$} \\
\hline 3 & 20 wt.\% MCM-41-HPW & HMF & Ethanol & $100^{\circ} \mathrm{C}, 12 \mathrm{~h}$ & 49.3 & {$[70]$} \\
\hline 4 & 40 wt.\% MCM-41-HPW & $\mathrm{HMF}$ & Ethanol & $100^{\circ} \mathrm{C}, 12 \mathrm{~h}$ & 83.4 & {$[70]$} \\
\hline 5 & $20 \% \mathrm{HSiW} / \mathrm{M}-\mathrm{Ns}$ & $\mathrm{HMF}$ & Ethanol & $90^{\circ} \mathrm{C}, 2 \mathrm{~h}$ & 70.1 & [71] \\
\hline 6 & $40 \% \mathrm{HSiW} / \mathrm{M}-\mathrm{Ns}$ & $\mathrm{HMF}$ & Ethanol & $90^{\circ} \mathrm{C}, 4 \mathrm{~h}$ & 77.4 & [71] \\
\hline 7 & $60 \% \mathrm{HSiW} / \mathrm{M}-\mathrm{Ns}$ & HMF & Ethanol & $90^{\circ} \mathrm{C}, 2 \mathrm{~h}$ & 65.6 & [71] \\
\hline 8 & $\mathrm{Ar}-\mathrm{SO}_{3} \mathrm{H}-\mathrm{SBA}-15$ & Fructose & Ethanol/DMSO & $116^{\circ} \mathrm{C}, 4 \mathrm{~h}$ & 63.4 & [66] \\
\hline 9 & USY & Fructose & Ethanol & $120^{\circ} \mathrm{C}, 25 \mathrm{~min}$ & 73.8 & [72] \\
\hline 10 & USY & Corn stover & Ethanol/THF & $168^{\circ} \mathrm{C}, 175 \mathrm{~min}$ & 21.8 & [38] \\
\hline 11 & $\mathrm{H}_{3} \mathrm{PW}_{12} \mathrm{O}_{40}$ & Fructose & Ethanol/THF & $130^{\circ} \mathrm{C}, 30 \mathrm{~min}$ & 76 & [55] \\
\hline 12 & $\mathrm{H}_{3} \mathrm{PW}_{12} \mathrm{O}_{40}$ & Sucrose & Ethanol/THF & $130^{\circ} \mathrm{C}, 30 \mathrm{~min}$ & 33 & [55] \\
\hline 13 & $\mathrm{H}_{3} \mathrm{PW}_{12} \mathrm{O}_{40}$ & Inulin & Ethanol/THF & $130^{\circ} \mathrm{C}, 30 \mathrm{~min}$ & 62 & [55] \\
\hline 14 & $\mathrm{Fe}_{3} \mathrm{O}_{4} @ \mathrm{SiO}_{2}-\mathrm{HPW}$ & HMF & Ethanol & $150^{\circ} \mathrm{C}, 11 \mathrm{~h}$ & 83.6 & [73] \\
\hline 15 & $\mathrm{Fe}_{3} \mathrm{O}_{4} @ \mathrm{SiO}_{2}-\mathrm{HPW}$ & Fructose & Ethanol & $100^{\circ} \mathrm{C}, 24 \mathrm{~h}$ & 54.8 & [73] \\
\hline 16 & 30 wt. $\%$ K-10 clay-HPW & HMF & Ethanol & $100^{\circ} \mathrm{C}, 10 \mathrm{~h}$ & 91.5 & [31] \\
\hline 17 & 30 wt. $\%$ K-10 clay-HPW & Fructose & Ethanol & $100^{\circ} \mathrm{C}, 10 \mathrm{~h}$ & 61.5 & [31] \\
\hline 18 & PY-PW-1 & HMF & Ethanol & $80^{\circ} \mathrm{C}, 24 \mathrm{~h}$ & 90 & [74] \\
\hline 19 & PY-PW-2 & $\mathrm{HMF}$ & Ethanol & $80^{\circ} \mathrm{C}, 24 \mathrm{~h}$ & 70 & [74] \\
\hline 20 & TEA-PW-1 & HMF & Ethanol & $80^{\circ} \mathrm{C}, 24 \mathrm{~h}$ & 59 & [74] \\
\hline 21 & TEA-PW-2 & $\mathrm{HMF}$ & Ethanol & $80^{\circ} \mathrm{C}, 24 \mathrm{~h}$ & 43 & {$[74]$} \\
\hline 22 & Silica- $\mathrm{SO}_{3} \mathrm{H}$ & HMF & Ethanol & $100^{\circ} \mathrm{C}, 24 \mathrm{~h}$ & 83.8 & [56] \\
\hline 23 & Silica- $\mathrm{SO}_{3} \mathrm{H}$ & Fructose & Ethanol & $100^{\circ} \mathrm{C}, 24 \mathrm{~h}$ & 63.1 & [56] \\
\hline 24 & Silica- $\mathrm{SO}_{3} \mathrm{H}$ & Sucrose & Ethanol & $100^{\circ} \mathrm{C}, 24 \mathrm{~h}$ & 34.9 & [56] \\
\hline 25 & Silica- $\mathrm{SO}_{3} \mathrm{H}$ & Inulin & Ethanol & $100^{\circ} \mathrm{C}, 24 \mathrm{~h}$ & 60.7 & [56] \\
\hline 26 & $\mathrm{OMC}-\mathrm{SO}_{3} \mathrm{H}$ & Fructose & Ethanol & $140^{\circ} \mathrm{C}, 24 \mathrm{~h}$ & 55.7 & [75] \\
\hline 27 & $\mathrm{OMC}-\mathrm{SO}_{3} \mathrm{H}$ & Sucrose & Ethanol & $140^{\circ} \mathrm{C}, 24 \mathrm{~h}$ & 26.8 & [75] \\
\hline 28 & $\mathrm{OMC}-\mathrm{SO}_{3} \mathrm{H}$ & Inulin & Ethanol & $140^{\circ} \mathrm{C}, 24 \mathrm{~h}$ & 53.6 & [75] \\
\hline 29 & T-CeMOF & Fructose & Ethanol/DMSO & $130^{\circ} \mathrm{C}, 16 \mathrm{~h}$ & 69.6 & [76] \\
\hline 30 & $\mathrm{FW}-\mathrm{SO}_{3} \mathrm{H}$ & Fructan-rich food & Ethanol & $140^{\circ} \mathrm{C}, 4 \mathrm{~h}$ & 49.4 & [77] \\
\hline 31 & $\mathrm{FW}-\mathrm{SO}_{3} \mathrm{H}$ & Fructan-rich food & Ethanol/DMSO & $140^{\circ} \mathrm{C}, 4 \mathrm{~h}$ & 52.1 & [77] \\
\hline 32 & $\mathrm{FW}-\mathrm{SO}_{3} \mathrm{H}$ & Fructan-rich food & Ethanol/THF & $140^{\circ} \mathrm{C}, 4 \mathrm{~h}$ & 35.7 & [77] \\
\hline 33 & $\mathrm{FW}-\mathrm{SO}_{3} \mathrm{H}$ & Fructan-rich food & Ethanol $/ \mathrm{H}_{2} \mathrm{O}$ & $140^{\circ} \mathrm{C}, 4 \mathrm{~h}$ & 48.7 & [77] \\
\hline 34 & $\mathrm{FW}-\mathrm{SO}_{3} \mathrm{H}$ & Fructan-rich food & Ethanol/DMSO/ $\mathrm{H}_{2} \mathrm{O}$ & $140^{\circ} \mathrm{C}, 4 \mathrm{~h}$ & 30.4 & [77] \\
\hline 35 & D-SPC & Fructose & Ethanol/THF & $140^{\circ} \mathrm{C}, 18 \mathrm{~h}$ & 68.8 & [67] \\
\hline 36 & PDVTA- $\mathrm{SO}_{3} \mathrm{H}$ & HMF & Ethanol & $110^{\circ} \mathrm{C}, 30 \mathrm{~min}$ & 87.7 & [78] \\
\hline 37 & MCC- $-\mathrm{SO}_{3} \mathrm{H}$ & Fructose & Ethanol & $120^{\circ} \mathrm{C}, 16 \mathrm{~h}$ & 63.2 & [79] \\
\hline 38 & $\mathrm{MCC}-\mathrm{SO}_{3} \mathrm{H}$ & Sucrose & Ethanol & $120^{\circ} \mathrm{C}, 16 \mathrm{~h}$ & 32.5 & [79] \\
\hline 39 & $\mathrm{MCC}-\mathrm{SO}_{3} \mathrm{H}$ & Inulin & Ethanol & $120^{\circ} \mathrm{C}, 16 \mathrm{~h}$ & 51.3 & [79] \\
\hline
\end{tabular}

synthesis. Xu et al. [72] and Chen et al. [38] used USY to obtain $73.8 \%$ and $21.8 \%$ of EMF from fructose in the ethanol system and corn stover in the ethanol/THF system, respectively.

\subsubsection{Heteropolyacid-Based Hybrid Catalysts.} Heteropolyacids (HPAs) are a type of oxygen-containing polyacids composed of heteroatoms (e.g., P, Si, Fe, and Co) and polyatoms (e.g., Mo, W, V, Nb, and Ta) by oxygen atom bridging connections in a certain structure [82]. HPAs have the following advantages when they are used as catalysts. Under mild conditions, they exhibit fast and reversible multielectron redox conversion and provide a strong Brønsted acidity [83]. Due to these excellent properties, HPAs are widely used in the preparation of EMF.

Yang et al. [55] used fructose, sucrose, and inulin as substrates to synthesise EMF under the conditions of microwave heating at $130^{\circ} \mathrm{C}$ within 30 min with $\mathrm{H}_{3} \mathrm{PW}_{12} \mathrm{O}_{40}$ as a catalyst. After continuous improvement of the tested plan, the solvent was changed from ethanol to a cosolvent system with THF, and the EMF yield increased from 65\% to $76 \%$ using fructose as the substrate. However, most HPAs are soluble acids, so they are difficult to separate, inconvenient for recycling, and easily corrode equipment. To overcome this trouble, many researchers loaded HPAs onto solid supports to form load-type HPAs. A load-type HPA $\left(\mathrm{H}_{4} \mathrm{SiW}_{12} \mathrm{O}_{40} / \mathrm{MCM}-41\right)$ was obtained by loading $\mathrm{H}_{4} \mathrm{SiW}_{12} \mathrm{O}_{40}$ on nano-MCM-41, and a satisfactory EMF yield (92\% HMF conversion and 84.1\% EMF selectivity) was obtained [71]. Furthermore, to better recover the catalyst, the catalyst can be magnetized by adding $\mathrm{Fe}_{3} \mathrm{O}_{4}$ into it. Wang et al. [73] first embedded $\mathrm{Fe}_{3} \mathrm{O}_{4}$ in silica to form silica-coated $\mathrm{Fe}_{3} \mathrm{O}_{4}$ nanoparticles, and then, HPW was loaded on it to synthesise $\mathrm{Fe}_{3} \mathrm{O}_{4} @ \mathrm{SiO}_{2}-\mathrm{HPW}$ with both catalytic activity and magnetic properties. They employed $\mathrm{Fe}_{3} \mathrm{O}_{4} @ \mathrm{SiO}_{2}-\mathrm{HPW}$ to catalyze HMF into EMF with a high yield (83.6\%) and observed a moderate EMF yield (54.8\%) from fructose. The 
$\mathrm{K}-10$ clay-HPW catalyst was prepared by fixing HPW on $\mathrm{K}-10$ clay as a carrier and used in the reaction process for the conversion of fructose and HMF to EMF by Liu et al. [31]. The EMF yield was $91.5 \%$ after $10 \mathrm{~h}$ for $100^{\circ} \mathrm{C}$ from HMF, and another was $61.5 \%$ after $24 \mathrm{~h}$ for $100^{\circ} \mathrm{C}$ from fructose through a one-pot method. Organic-heteropolyacid (organic-HPA) hybrids can be prepared by simple self-assembly of electrostatic interactions [84]. Wang et al. [74] used HPW and pyridine (PY) or triethylamine (TEA) through the selfassembly method to prepare a string of organic-inorganic acidic hybrids (PY-HPW-x and TEA-HPW-x). PY-HPW-1 had higher acidity and a tiny particle size and exhibited great catalytic performance for HMF to EMF $(90 \%)$ under $80^{\circ} \mathrm{C}$ after $24 \mathrm{~h}$. Carbonaceous materials as supporters to accept HPAs were reported by García-Bosch et al. [85]. They loaded $15 \mathrm{wt} \%$ phosphotungstic acid (TPA) or tungstosilicic acid (STA) onto activated carbon (AC) and graphite (HSAG) to prepare the catalysts TPA-AC/HSAG and STA-AC/HSAG. They exploited STA-HSAG to get nearly a $50 \%$ yield of EMF + EMFDA from fructose in ethanol. Here is a noteworthy research, which obtained the highest EMF yield (over 99\%) and 100\% HMF conversion, by Yang et al. [11]. They accurately adjusted the content of niobium and molybdenum to prepare a series of layered-niobium-molybdate solid acids, which could control the amount of Brønsted acid and mezzanine space coupled with clear Lewis acid sites.

4.2.3. $\mathrm{SO}_{3} \mathrm{H}$-Based Catalysts. Brønsted acid has a significant catalytic performance that can etherify HMF into EMF and the alcoholysis of fructose and other carbohydrates to form EMF. Sulfuric acid is a typical Brønsted acid; therefore, the introduction of sulfonic acid groups into the supporters to obtain solid- $\mathrm{SO}_{3} \mathrm{H}$-based catalysts is an effective program, especially for the preparation of EMF [86]. A proton acid solid catalyst with high acidity can be produced by loading sulfonic acid groups onto supporters, which is defined as a $-\mathrm{SO}_{3} \mathrm{H}$-based catalyst. These typical catalysts have many advantages such as high catalytic capability, easy separation and recycling, no-corrode equipment, and environmental friendliness. Furthermore, their catalyst activity can be adjusted by the amount of supported acid [87].

Initially, Liu et al. [56] prepared a silica- $\mathrm{SO}_{3} \mathrm{H}$ catalyst, which was obtained by immobilizing sulfonic acid to silica. The catalyst could promote the transformation of HMF, fructose, glucose, sucrose, cellobiose, and inulin into EMF in the presence of a silica- $\mathrm{SO}_{3} \mathrm{H}$ catalyst in ethanol. Also, the EMF yields from HMF, fructose, sucrose, and inulin were $83.8 \%, 63.1 \%, 34.9 \%$, and $60.7 \%$, respectively. However, glucose and cellobiose as feedstocks detected no EMF. It is indicated that the silica- $\mathrm{SO}_{3} \mathrm{H}$ catalyst which had Brønsted acid sites could carry out hydrolysis and etherification reactions but could not isomerize glucose. Morales et al. [66] successfully fabricated a sulfonic acid-functionalized catalyst $\left(\mathrm{Ar}-\mathrm{SO}_{3} \mathrm{H}-\mathrm{SBA}-15\right)$ by loading arene sulfonic acid on modified SBA-15 mesostructured silica. They used response surface methodology to optimize the catalyst loading, temperature, and cosolvent concentration (DMSO) of reaction by $\mathrm{Ar}_{-} \mathrm{SO}_{3} \mathrm{H}-\mathrm{SBA}-15$. The optimal reaction conditions $\left(116^{\circ} \mathrm{C}, 13.5 \mathrm{~mol} \%\right.$ catalyst loading, and 8.3 vol\% of DMSO for $4 \mathrm{~h}$ ) could obtain a $63.4 \%$ yield of EMF in the medium of ethanol from fructose.

Carbon-based catalysts to hold the sulfonic acid group have been developed by researchers in recent years. Ordered mesoporous carbon (OMC) was used to support chlorosulfonic acid, and a sulfonic acid-functionalized OMC catalyst $\left(\mathrm{OMC}-\mathrm{SO}_{3} \mathrm{H}\right)$ was synthesised by Wang et al. [75]. Fructose, sucrose, and inulin were successfully transformed into EMF by using $\mathrm{OMC}-\mathrm{SO}_{3} \mathrm{H}$, and yields of $55.7 \%, 26.8 \%$, and $53.6 \%$ were obtained, respectively, at more severe conditions $\left(140^{\circ} \mathrm{C}, 24 \mathrm{~h}\right)$ in ethanol. Another carbon- $\mathrm{SO}_{3} \mathrm{H}-$ based catalyst was prepared by Antunes et al. [88]. They used the reduction of graphene oxide as the carbon-based catalyst and sulfuric acid as the sulfonating agent to prepare the catalyst S-RGO and found that S-RGO had more remarkable catalytic performance than other carbon- $\mathrm{SO}_{3} \mathrm{H}$-based catalysts and the commercial acid resin Amberlyst-15. The high efficiency of the catalyst is due to its different acid sites $\left(-\mathrm{SO}_{3} \mathrm{H},-\mathrm{COOH}\right.$, and $\left.-\mathrm{OH}\right)$ with the $2 \mathrm{D}$ structure of graphene that could enhance the accessibility of the active sites.

A metal-organic framework- (MOF-) derived carbon$\mathrm{SO}_{3} \mathrm{H}$-based catalyst was prepared by Wang et al. [89]. They utilized $\mathrm{Cu}$-benzene-1,3,5-tricarboxylate (Cu-BTC) as a predecessor to direct pyrolysis and then used sulfuric acid to treat the sample to obtain the $\mathrm{C}-\mathrm{SO}_{3} \mathrm{H}$ catalyst. A normal yield of $71 \%$ for HMF conversion into EMF was detected over $\mathrm{C}-\mathrm{SO}_{3} \mathrm{H}$ at $100^{\circ} \mathrm{C}$ for $6 \mathrm{~h}$ with ethanol as a solvent. A novel Ce-MOF doped with taurine (T-CeMOF) was fabricated by bonding Ce to 1,3,5-benzenetricarboxylic acid (BTC) also accompanied by the taurine in this system, which transformed fructose into $69.6 \% \mathrm{EMF}$ at $130^{\circ} \mathrm{C}$ after $16 \mathrm{~h}$ in the ethanol/DMSO medium [76]. Catalyst characterization indicated that the surface of T-CeMOF existed with massive swinging of $-\mathrm{COOH}$, and the $-\mathrm{SO}_{3} \mathrm{H}$ of taurine was successfully introduced into T-CeMOF. These were beneficial to the catalytic activity of T-CeMOF in the conversion of HMF to EMF.

Biomass- $\mathrm{SO}_{3} \mathrm{H}$-based catalysts were prepared by Zhao et al. [68] and Wen et al. [90], and they both directly used waste Camellia oleifera shells to fabricate biobased sulfonic acid-functionalized catalysts by a hydrothermal sulfonation. These two biomass- $\mathrm{SO}_{3} \mathrm{H}$-based catalysts had spherical microstructures and abundant surface- $\mathrm{SO}_{3} \mathrm{H}$, showing excellent catalytic performance. Simultaneously, the EMF yield was significantly affected by the sulfonation conditions of the biomass- $\mathrm{SO}_{3} \mathrm{H}$-based catalysts preparation process. In addition, lignosulfonate [91], glucose-derived magnetic solid acid [92], food waste-derived solid acid [77], and cellulose sulfuric acid [93] were used as biomass sulfonic acidfunctionalized catalysts to obtain EMF.

Organic polymer-based catalysts to support $-\mathrm{SO}_{3} \mathrm{H}$ can be used to synthesise a novel solid organic polymer catalyst which includes the sulfonic acid group. Dai et al. [67] reported a sulfonated organic polymer catalyst (D-SPC) which had a special double hydrogen-bonded structure. Also, it was prepared by copolymerization of aniline (AN) and 2,2'benzidinedisulfonic acid (BDSA) to form SPC and then treated with 1,3-dihydroxypropan-2-one (DHA) to form 
D-SPC. They found that DHA bonded with SPC through carbonyl and sulfonic acid groups, forming a hydrogen bond between the two (Scheme 3). Also, adjusting the dosage of DHA, AN, and BDSA could control the acid strength and density of D-SPC that could pick the yield of EMF (68.8\%). Xiang et al. [78] also assembled a sulfonic acid-based porous organic polymer (PDVTA- $\mathrm{SO}_{3} \mathrm{H}$ ); they first synthesised PDVTA by mixing divinylbenzene (DVB) and triallylamine (TAA) by a solvothermal copolymerization method, and then, $\mathrm{PDVTA}-\mathrm{SO}_{3} \mathrm{H}$ was prepared by the sulfonation process of PDVTA. They used the Box-Behnken response surface method to adjust the reaction conditions and observed a 99.8\% HMF conversion and 87.5\% EMF yield at $110^{\circ} \mathrm{C}$ within $30 \mathrm{~min}$.

Magnetic- $\mathrm{SO}_{3} \mathrm{H}$-based catalysts can be simply extracted from the reaction system using a permanent magnet, improving catalyst recovery rate and showing high stability in the cycling experiment. In recent years, the synthesis of magnetic sulfonic acid catalysts by adding magnetic nanoparticles has become the focus. Originally, inspired by the $\mathrm{Fe}_{3} \mathrm{O}_{4} @ \mathrm{SiO}_{2}$-HPW developed by Wang et al. [73], $\mathrm{Fe}_{3} \mathrm{O}_{4} @$ $\mathrm{SiO}_{2}-\mathrm{SO}_{3} \mathrm{H}$ NPs were prepared by Zhang et al. [29]. $\mathrm{Fe}_{3} \mathrm{O}_{4} @$ $\mathrm{SiO}_{2}-\mathrm{SO}_{3} \mathrm{H}$ was used to convert HMF, fructose, and inulin into EMF, and the yields were $89.3 \%, 72.5 \%$, and $63.3 \%$, respectively. After this, Yuan et al. [94], Thombal et al. [92], and Bai et al. [95] changed $\mathrm{SiO}_{2}$ to glucose, and they all successfully synthesised a carbon-based magnetic sulfonic acid-functionalized catalyst to produce EMF. Furthermore, Chen et al. [79] utilized different biomass-based compounds such as glucose, sucrose, starch, and cellulose to synthesise carbon-based sulfonic acid-functionalized catalysts, namely, GC- $\mathrm{SO}_{3} \mathrm{H}, \mathrm{SuC}_{-} \mathrm{SO}_{3} \mathrm{H}, \mathrm{StC}-\mathrm{SO}_{3} \mathrm{H}$, and CC-SO ${ }_{3} \mathrm{H}$, respectively. Also, $\mathrm{CC}-\mathrm{SO}_{3} \mathrm{H}$ was magnetized to generate MCC$\mathrm{SO}_{3} \mathrm{H}$, which had $-\mathrm{COOH},-\mathrm{SO}_{3} \mathrm{H}$, and phenolic $-\mathrm{OH}$ groups. It could catalyze fructose, sucrose, and inulin to produce $63.2 \%, 32.5 \%$, and $51.3 \%$ EMF, respectively, at $120^{\circ} \mathrm{C}$ for $16 \mathrm{~h}$ in an ethanol medium. In summary, magnetic $-\mathrm{SO}_{3} \mathrm{H}$-based materials can be used as efficient, highly stable, and recyclable catalysts for the transformation of carbohydrates into EMF.

4.3. Ionic Liquid Catalysts. Mixing of organic cations and inorganic anions can yield typical ionic liquids (ILs), which have outstanding physical and chemical attributes, such as great thermochemical stability, low melting point, and great solubility [102]. ILs are widely used in a range of biomass conversions as a solvent and catalyst, showing great catalytic potential in etherification reactions [103, 104]. Table 4 shows the preparation of EMF from different ILs.

Yin et al. [54] successfully immobilized polyionic liquid on a magnetic $\mathrm{Fe}_{3} \mathrm{O}_{4} @ \mathrm{SiO}_{2}$ material to prepare an acid recyclable catalyst $\left(\mathrm{Fe}_{3} \mathrm{O}_{4} @ \mathrm{SiO}_{2}\right.$-SH-Im- $\left.\mathrm{HSO}_{4}\right)$. It was applied to obtain EMF, with yields of $89.6 \%$ from HMF, $60.4 \%$ from fructose, $56.1 \%$ from inulin, and $34.4 \%$ from sucrose. In addition to being a catalyst, ionic liquids can also be used as cosolvents for the synthesis of EMF. In 2016, Guo et al. [40] investigated whether under milder conditions, using an IL which had a hydrogen sulfate, both as a cosolvent and a catalyst, could directly catalyze the fructose being converted to EMF in the ethanol system. They found that the yield of fructose being converted to $\mathrm{EMF}$ reached $83 \%$ in the $\left[\mathrm{C}_{4} \mathrm{mim}\right]\left[\mathrm{HSO}_{4}\right]$-ethanol system at $130^{\circ} \mathrm{C}$ for $20 \mathrm{~min}$, due to the acidity of anion and the stable hydrogen bond formed between the ionic liquid and HMF (Scheme 4). On this basis, in 2017, they synthesised another ionic liquid ([BMIM] $\left[\mathrm{HSO}_{4}\right]$ ) [43] to analyze the conversion efficiency of inulin and sucrose to EMF. $77 \%$ and $43 \%$ of EMF were detected from inulin and sucrose, respectively, at $130^{\circ} \mathrm{C}$ within $30 \mathrm{~min}$ in the $[\mathrm{BMIM}]\left[\mathrm{HSO}_{4}\right]$-ethanol system. It was deemed that the hydrogen sulfate group of $[\mathrm{BMIM}]\left[\mathrm{HSO}_{4}\right]$ could promote the breakage of glycosidic bonds, dehydration, and etherification of fructose and glucose isomerization to fructose. But, the rate of detected EMF was only $8 \%$ when changing glucose as the substrate. So, after this, to increase the efficiency of glucose conversion, $\mathrm{AlCl}_{3}$ was added to the [BMIM] $\left[\mathrm{HSO}_{4}\right]$-ethanol system to form the $\mathrm{AlCl}_{3}$-[BMIM] $\left[\mathrm{HSO}_{4}\right]$-ethanol system [96]. $\mathrm{AlCl}_{3}$ could enhance the isomerization of glucose by the Lewis acid site present in $\mathrm{AlCl}_{3}$, and the EMF yield was $37 \%$ from glucose via a onepot reaction. Nonfood biomass (mushroom) as feedstuff could be converted into EMF (33\%) using IL as a catalyst at $120^{\circ} \mathrm{C}$ after $20 \mathrm{~h}$ [97]. The IL was compounded by $\mathrm{N}$, $\mathrm{N}$-dimethylacetamide (DMA) as a cation and methanesulfonic acid as an anion named $[\mathrm{DMA}]\left[\mathrm{CH}_{3} \mathrm{SO}_{3}\right]$.

4.4. Brønsted and Lewis Acid Bifunctional Catalysts. The single-acid catalysts as described in Sections 4.1, 4.2 and 4.13 can hardly convert glucose or glucose-based products to produce EMF, which only have Brønsted acid sites. Due to the lack of Lewis acid species, the isomerization of glucose hardly occurs, and it is more inclined to produce ethyl glucoside catalyzed by Brønsted acid. With the intent of raising the efficiency of glucose-based conversion to EMF, the researchers developed mixed-acid catalysts for this purpose, which are summarized in Table 4.

Mixed acids have been used to catalyze the synthesis of EMF. For example, Xin et al. [48] utilized paraformaldehyde (POM) and polymerizing p-toluenesulfonic acid (PTSA) in $\mathrm{H}_{2} \mathrm{SO}_{4}$ to synthesise a mixed-acid catalyst (PTSA-POM) which contained Brønsted acid sites. Compared with a single-acid catalyst, PTSA-POM combined with $\mathrm{AlCl}_{3} \cdot 6 \mathrm{H}_{2} \mathrm{O}$ could obtain a satisfying EMF yield (30.6\%) from glucose. An optimistic EMF yield was obtained from glucose-based saccharides, such as corn starch (36.9\%), amylose (39.8\%), and amylopectin (34.7\%), by using a mixed-acid catalyst that contains $\mathrm{H}_{3} \mathrm{PO}_{4}$ and $\mathrm{Al}_{2}\left(\mathrm{SO}_{4}\right)_{3}$ in an ethanol/DMSO medium [28].

Different from a simple mixed state, grafting two acids into a whole seems to be a better way. Generally, zeolite molecular sieve catalysts contain Brønsted acid species Al$\mathrm{O}(\mathrm{H})-\mathrm{Si}$ (framework four-coordinate aluminum), and Lewis acid species Al- (framework three-coordinate aluminum) can be obtained after high-temperature dealumination [105]. These bifunctional acid catalysts have been used to synthesise EMF from glucose-based carbohydrates. USY and $\beta$ zeolite $(\mathrm{DeAl}-\mathrm{H}-\beta)$ that have been dealuminated at a high 
<smiles>CNc1ccc(Nc2ccc(-c3ccc(Nc4ccc(N5CCN5CCNc5ccc(Nc6ccc(S(=O)(=O)O)cc6)cc5S(=O)(=O)O)cc4)cc3S(=O)(=O)O)c(S(=O)(=O)O)c2)cc1-c1ccc(N)cc1S(=O)(=O)O</smiles>

AN

BDSA

SPC

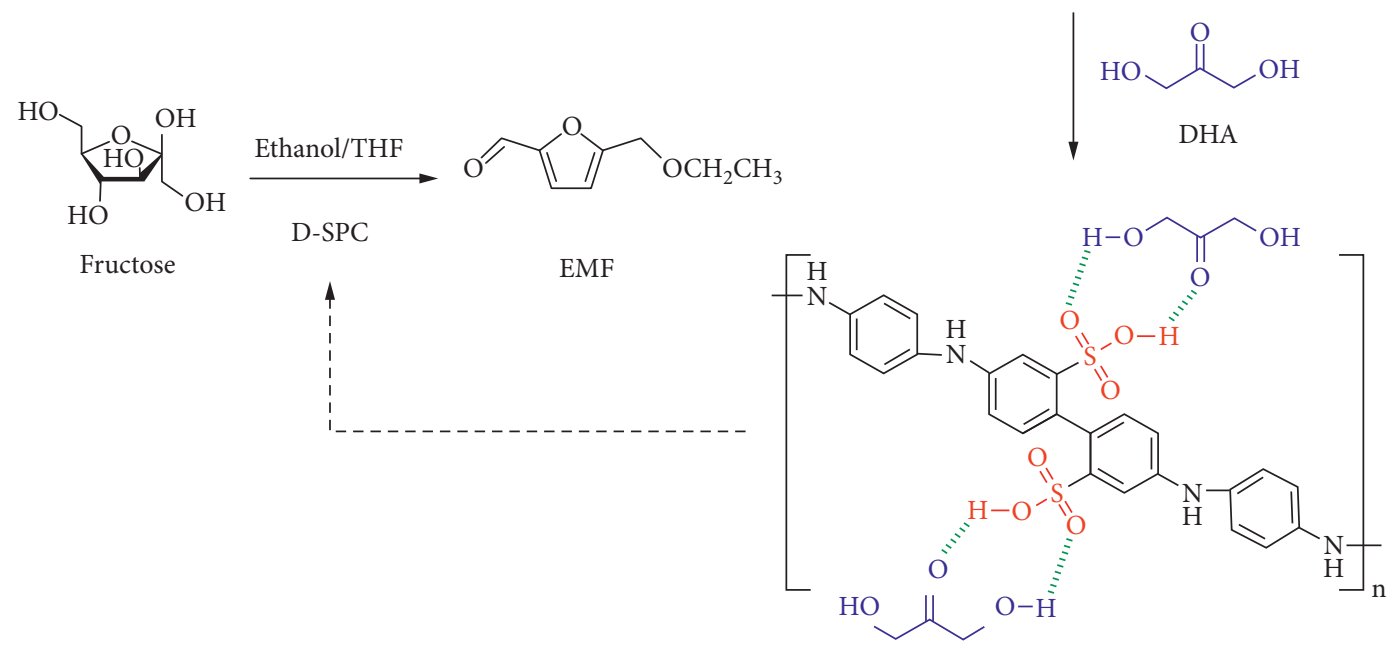

D-SPC

Scheme 3: The synthesis of D-SPC used for catalytic conversion of fructose to EMF.

TABle 4: Ionic liquid, mixed-acid catalyst, and deep eutectic solvents used for EMF synthesis.

\begin{tabular}{|c|c|c|c|c|c|c|}
\hline Entry & Catalyst & Feedstock & Solvent & Reaction condition & Yield (\%) & Ref. \\
\hline 1 & {$\left[\mathrm{C}_{4} \mathrm{mim}\right]\left[\mathrm{HSO}_{4}\right]$} & HMF & Ethanol & $130^{\circ} \mathrm{C}, 20 \mathrm{~min}$ & 83 & {$[40]$} \\
\hline 2 & {$[\mathrm{BMIM}]\left[\mathrm{HSO}_{4}\right]$} & Inulin & Ethanol & $130^{\circ} \mathrm{C}, 30 \mathrm{~min}$ & 77 & [43] \\
\hline 3 & {$[\mathrm{BMIM}]\left[\mathrm{HSO}_{4}\right]$} & Sucrose & Ethanol & $130^{\circ} \mathrm{C}, 30 \mathrm{~min}$ & 43 & [43] \\
\hline 4 & {$[\mathrm{BMIM}]\left[\mathrm{HSO}_{4}\right]$} & Glucose & Ethanol & $130^{\circ} \mathrm{C}, 30 \mathrm{~min}$ & 8 & [43] \\
\hline 5 & {$[\mathrm{BMIM}]\left[\mathrm{HSO}_{4}\right] / \mathrm{AlCl}_{3}$} & Glucose & Ethanol & $130^{\circ} \mathrm{C}, 30 \mathrm{~min}$ & 37 & [96] \\
\hline 6 & {$[\mathrm{DMA}]\left[\mathrm{CH}_{3} \mathrm{SO}_{3}\right]$} & Mushroom & Ethanol & $120^{\circ} \mathrm{C}, 20 \mathrm{~h}$ & 33 & [97] \\
\hline 7 & PTSA-POM $/ \mathrm{AlCl}_{3} \cdot 6 \mathrm{H}_{2} \mathrm{O}$ & Glucose & Ethanol $/ \mathrm{H}_{2} \mathrm{O}$ & $150^{\circ} \mathrm{C}, 30 \mathrm{~min}$ & 30.6 & [48] \\
\hline 8 & DeAl-H- $\beta$ & Glucose & Ethanol & $125^{\circ} \mathrm{C}, 10 \mathrm{~h}$ & 41 & [80] \\
\hline 9 & SnSTA & Glucose & Ethanol & $140^{\circ} \mathrm{C}, 9 \mathrm{~h}$ & 41 & [98] \\
\hline 10 & $\mathrm{MFI}-\mathrm{Sn} / \mathrm{Al}$ & Glucose & Ethanol & $140^{\circ} \mathrm{C}, 9 \mathrm{~h}$ & 44 & [58] \\
\hline 11 & BFC-3 & Glucose & Ethanol/THF & $100^{\circ} \mathrm{C}, 10 \mathrm{~h}$ & 48.1 & [50] \\
\hline 12 & BFC-3 & Cellobiose & Ethanol/THF & $100^{\circ} \mathrm{C}, 10 \mathrm{~h}$ & 37.1 & [50] \\
\hline 13 & $\mathrm{Zn}-\mathrm{S}-\mathrm{C}$ & Glucose & Ethanol/THF & $98^{\circ} \mathrm{C}, 47 \mathrm{~min}$ & 80.9 & [27] \\
\hline 14 & $\mathrm{Zn}-\mathrm{S}-\mathrm{C}$ & Cellobiose & Ethanol/THF & $98^{\circ} \mathrm{C}, 47 \mathrm{~min}$ & 74.6 & [27] \\
\hline 15 & $\mathrm{Zn}-\mathrm{SO}_{3} \mathrm{H}-\mathrm{GR}$-carbon & Glucose & Ethanol/THF & $106^{\circ} \mathrm{C}, 72 \mathrm{~min}$ & 86.3 & [99] \\
\hline 16 & ChCl-oxalic (DES) & Fructose & Ethanol & $70^{\circ} \mathrm{C}, 3 \mathrm{~h}$ & 74 & {$[100]$} \\
\hline 17 & DES/Amberlyst- 15 & Fructose & Ethanol & $100^{\circ} \mathrm{C}, 12 \mathrm{~h}$ & 77.3 & {$[101]$} \\
\hline 18 & DES/Amberlyst-15 & Inulin & Ethanol & $100^{\circ} \mathrm{C}, 12 \mathrm{~h}$ & 65.2 & {$[101]$} \\
\hline 19 & DES/Amberlyst- 15 & Sucrose & Ethanol & $100^{\circ} \mathrm{C}, 12 \mathrm{~h}$ & 50.2 & {$[101]$} \\
\hline 20 & DES/Amberlyst-15 & Glucose & Ethanol & $100^{\circ} \mathrm{C}, 12 \mathrm{~h}$ & 46.7 & {$[101]$} \\
\hline
\end{tabular}




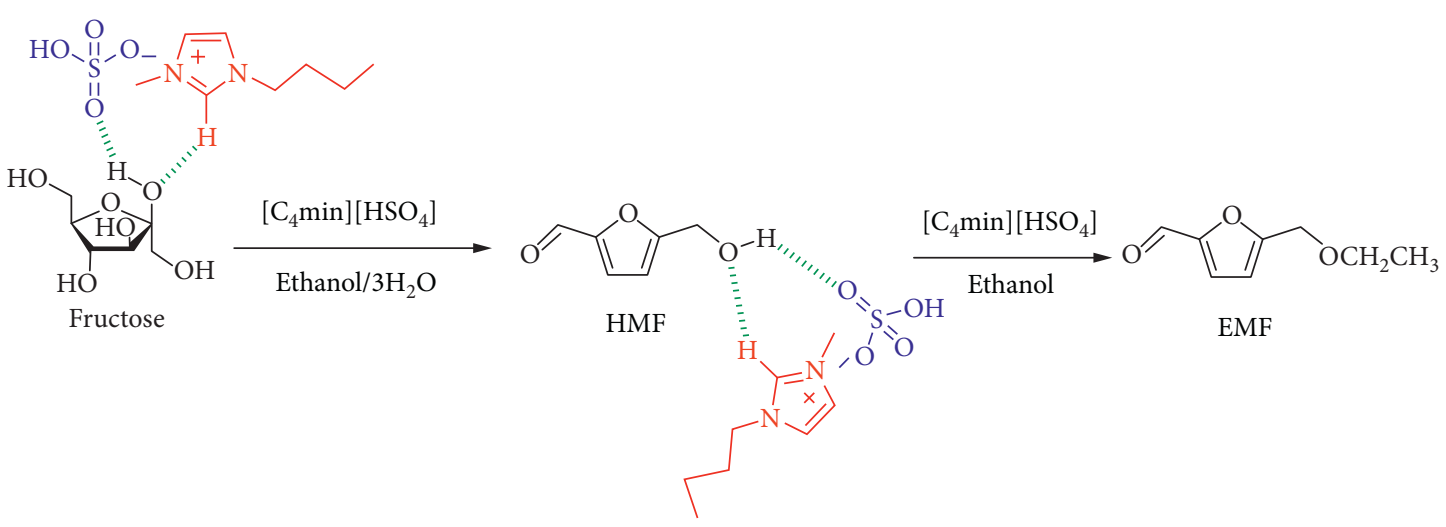

Scheme 4: The conversion of fructose to EMF catalyzed by $\left[\mathrm{C}_{4} \mathrm{mim}\right]\left[\mathrm{HSO}_{4}\right]$.

temperature can obtain 21.8\% EMF yield from corn stover and $41 \%$ EMF yield from glucose, respectively $[38,80]$. In addition, the introduction of additional metal species in the zeolites can also be used as Lewis acid. For example, the Lewis acid species $\mathrm{Sn}$ - and $\mathrm{Al}$ - were coloaded onto zeolite to form a bifunctional acid catalyst named MFI-Sn/Al [58]. It can provide $44 \%$ EMF yield from glucose. It can also introduce Brønsted and Lewis acids into zeolite at the same time, like SnSTA, which was synthesised by loading $\mathrm{H}_{4}\left[\mathrm{Si}\left(\mathrm{W}_{3} \mathrm{O}_{10}\right)_{4}\right]$ and $\mathrm{SnCl}_{4}$ onto SBA-15, which generated $41 \%$ EMF yield from glucose [98]. A soft template HIPE was used to support the sulfonic acid group and $\mathrm{Cr}^{3+}$ to synthesise a BFC-3 catalyst (Scheme 5), and $48.1 \%$ (glucose) and $37.1 \%$ (cellobiose) EMF yield were detected by using it [50]. Furthermore, Brønsted and Lewis acids can also be grafted into carbon-based materials. An amazing EMF yield was observed by utilizing a Zn-S-C catalyst from glucose-based carbohydrates, such as cellobiose $(74.6 \%)$ and glucose (80.9\%) [27]. Zn-S-C was formed by coloading $\mathrm{ZnO}$ and 2hydroxyethylsulfonic acid onto carbon-based material. Also, $\mathrm{ZnO}$ provides $\mathrm{Zn}^{2+}$ (Lewis acid site), while 2-hydroxyethylsulfonic provides $-\mathrm{SO}_{3} \mathrm{H}$ (Brønsted acid site). Another higher EMF yield $(86.3 \%)$ was obtained from glucose by using $\mathrm{Zn}-\mathrm{SO}_{3} \mathrm{H}$-GR-carbon, which includes both Brønsted $\left(-\mathrm{SO}_{3} \mathrm{H}\right)$ and Lewis $(\mathrm{Zn}-)$ acid species [99].

4.5. Deep Eutectic Solvents (DESs). DESs are new-generation solvents synthesised at the beginning of this century, which are a mixture of hydrogen bond acceptors (HBAs; e.g., the most typical is choline chloride) and hydrogen bond donors (HBDs; e.g., metal salts and their halides, polyols, and organic acids) [106]. They have the same excellent solvent characteristics as ILs, including low melting point, low viscosity, and high thermal stability [107]. Besides, DESs also have the advantages such as simple synthesis steps, low cost, being renewable, low toxicity, and biodegradable characteristics [108]. Table 4 summarizes some DESs used in EMF synthesis systems.

Currently, there are few studies on the use of DESs to prepare EMF from carbohydrates. Gawade et al. [100] used a variety of dicarboxylic acids (e.g., oxalic acid, malic acid, malonic acid, tartaric acid, itaconic acid, and succinic acid) combined with choline chloride ( $\mathrm{ChCl}$ ) to form a variety of DESs. Then, they used these DESs for the one-pot transformation of fructose into EMF in an ethanol medium under microwave radiation. A series of polar intermediates are produced in these processes. It was found that these polar intermediates could be stabilized by DESs, which are polar; thereby, DESs could enhance EMF selectivity. Among these DESs, ChCl-oxalic showed the most excellent catalytic performance, obtaining $74 \% \mathrm{EMF}$ yield at $70^{\circ} \mathrm{C}$ for $3 \mathrm{~h}$. Some studies showed that the DESs system could prevent the further hydration of HMF to produce byproducts, so this system is conducive to the acquisition of high-yield HMF $[109,110]$. According to this, Zuo et al. [101] developed a two-step method to convert carbohydrates into EMF. In the first step, the carbohydrates were dehydrated to form HMF in the DESs system. After that, the HMF was dissolved into methyl cyanide for the next esterification reaction to form EMF. The final EMF yield was $77.3 \%$ from fructose, $65.2 \%$ from inulin, $50.2 \%$ from sucrose, and $46.7 \%$ from glucose.

\section{Solvent Systems}

Except for feedstocks and catalysts, solvents also play a necessary role in the preparation of EMF. They can dissolve the feedstock, as well as bring the feedstock and the catalyst fully in contact to increase the mass transfer coefficient. In some way, a better solvent can raise the yield of EMF, and many solvents or cosolvents have been investigated for the manufacture of EMF, such as ethanol, DMSO, and THF. Table 5 summarizes the influence of various solvents on the EMF yield.

5.1. Ethanol System. Ethanol is the most common solvent used for the preparation of EMF. As a necessary reactant in the one-pot EMF process, it is widely sourced, cheap, nonpolluting, and easy to recycle. In the current research on the preparation of EMF, many researchers used ethanol as a solvent [92, 93], and the HMF etherification reaction was directly carried out, accompanied by ethanol under heating and acidic conditions, with the highest yield of 92.9\% [47]. Another satisfactory EMF yield (85.5\%) was obtained in the reaction of the ethanol system from $\mathrm{HMF}$ at $80^{\circ} \mathrm{C}$ for $11 \mathrm{~h}$ with the existence of an LS- $\mathrm{SO}_{3} \mathrm{H}$ catalyst [91]. 

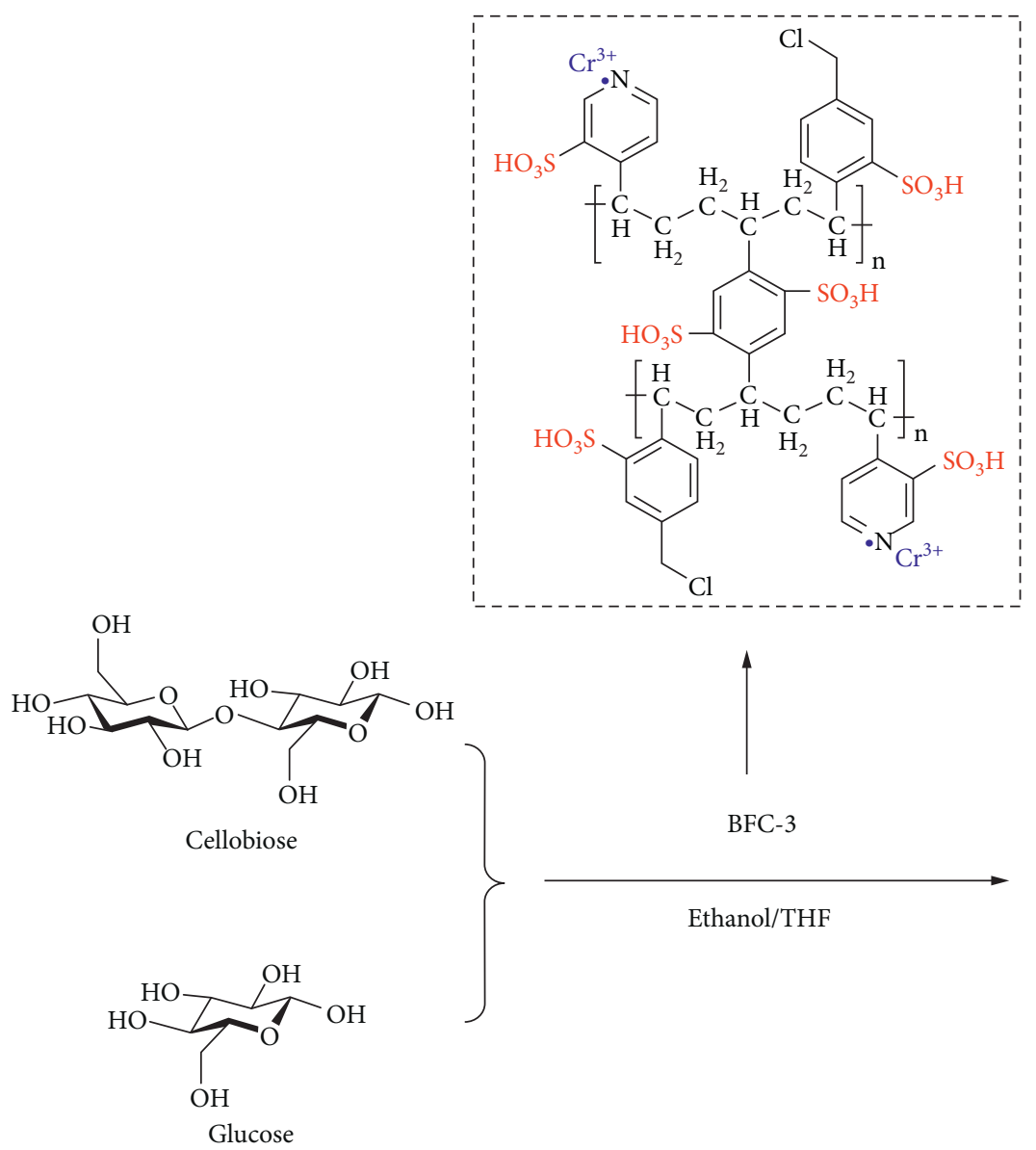

SCHeme 5: The transformation of cellobiose and glucose to EMF catalyzed by BFC-3.

TABLE 5: Various solvents used for EMF synthesis.

\begin{tabular}{|c|c|c|c|c|c|c|}
\hline Entry & Solvent & Feedstock & Catalyst & Reaction condition & Yield (\%) & Ref. \\
\hline 1 & Ethanol & HMF & $\mathrm{AlCl}_{3}$ & $100^{\circ} \mathrm{C}, 5 \mathrm{~h}$ & 92.9 & {$[47]$} \\
\hline 2 & Ethanol & Fructose & $\mathrm{AlCl}_{3}$ & $100^{\circ} \mathrm{C}, 11 \mathrm{~h}$ & 71.2 & {$[47]$} \\
\hline 3 & Ethanol & Glucose & $\mathrm{AlCl}_{3}$ & $100^{\circ} \mathrm{C}, 11 \mathrm{~h}$ & 38.4 & [47] \\
\hline 4 & Ethanol & HMF & $\mathrm{LS}-\mathrm{SO}_{3} \mathrm{H}$ & $80^{\circ} \mathrm{C}, 11 \mathrm{~h}$ & 85.8 & [91] \\
\hline 5 & Ethanol & Fructose & HCP-1 & $105^{\circ} \mathrm{C}, 12 \mathrm{~h}$ & 43.7 & [111] \\
\hline 6 & Ethanol/DMSO $(8: 2)$ & Fructose & HCP-1 & $105^{\circ} \mathrm{C}, 8 \mathrm{~h}$ & 78.9 & [111] \\
\hline 7 & Ethanol & Fructose & $\mathrm{H}_{3} \mathrm{PW}_{12} \mathrm{O}_{40}$ & $130^{\circ} \mathrm{C}, 30 \mathrm{~min}$ & 65 & {$[55]$} \\
\hline 8 & Ethanol/THF $(5: 3)$ & Fructose & $\mathrm{H}_{3} \mathrm{PW}_{12} \mathrm{O}_{40}$ & $130^{\circ} \mathrm{C}, 30 \mathrm{~min}$ & 76 & [55] \\
\hline 9 & Ethanol/GVL $(1: 1)$ & Fructose & $\mathrm{MHGC}-\mathrm{SO}_{3} \mathrm{H}$ & $120^{\circ} \mathrm{C}, 24 \mathrm{~h}$ & 67.4 & [95] \\
\hline
\end{tabular}

5.2. Cosolvent System. In an attempt to raise the EMF yield, adding a cosolvent is a common method. The addition of a suitable cosolvent under the same reaction conditions can significantly increase the EMF yield, and the commonly used cosolvents usually include DMSO, THF, and GVL. It was indicated that the additive of DMSO could promote the formation of EMF and reduce the formation of byproducts [66]. Zhang et al. [111] found that, under the same reaction system, the yield of EMF in the ethanol system was $43.7 \%$, and when the solvent was changed to ethanol/DMSO $(8: 2)$, the yield of EMF was greatly improved to $78.9 \%$. THF could also effectively increase the yield of EMF and inhibit side reactions. Yang et al. [55] used fructose to prepare EMF by the one-pot method, and the yield in the ethanol system was $65 \%$. After changing the solvent system to ethanol/THF (5: 3 ), the yield of EMF was remarkably raised to $76 \%$. Similarly, GVL could also significantly enhance the EMF yield. Bai et al. [95] found that compared with pure ethanol solvents, GVL could provide a hydrophobic environment for the reaction system and reduce the production of humus. Under the most appropriate reaction system, the EMF yield of the ethanol/GVL solvent system could reach $67.4 \%$. 


\section{Conclusions}

The conversion of various carbohydrates catalyzed by Brønsted acid and Lewis acid into a promising fuel additive EMF has made significant progress in the past few decades. Generally, HMF as a substrate can obtain a high EMF yield. However, the higher cost limits its industrial development. Furthermore, fructose-based saccharides (e.g., fructose, sucrose, and inulin) used as substrates produced EMF in higher yields than glucose-based ones (e.g., glucose, cellobiose, cellulose, and starch). This is because glucose-based saccharide is more difficult to be dehydrated, and glucose needs to be isomerized in the presence of Lewis acid before forming fructose. The use of solid catalysts can make the catalysts reusable, and magnetizing the solid catalysts can make the separation process simpler. Yet, most of the current catalysts generally have the disadvantages of the complex preparation process, such as high cost or low catalytic activity and selectivity, especially for glucose-based carbohydrates as the reaction substrates. The use of a cosolvent can effectively improve the selectivity and yield of EMF, but the existence of a cosolvent increases the difficulty of the separation and purification process, with potentially increased toxicity of the reaction system. Therefore, the development of efficient, economical, and recyclable solid catalysts containing both Brønsted and Lewis acid sites for the conversion of glucose-based carbohydrates is still the main future research direction

\section{Conflicts of Interest}

The authors declare no conflicts of interest.

\section{Authors' Contributions}

Dayong Yu and Xiaofang Liu contributed equally to this work.

\section{Acknowledgments}

This work was financially supported by the scientific research funds of Guiyang University (GYU-KY-[2021]), the Guizhou Provincial Key Laboratory for Rare Animal and Economic Insects of the Mountainous Region ([2018]5102), and the National Natural Science Foundation of China (22065004).

\section{References}

[1] J. P. M. Sanders, J. H. Clark, G. J. Harmsen et al., "Process intensification in the future production of base chemicals from biomass," Chemical Engineering and Processing: Process Intensification, vol. 51, pp. 117-136, 2012.

[2] P. Gallezot, "Conversion of biomass to selected chemical products," Chemical Society Reviews, vol. 41, no. 4, pp. 1538-1558, 2012.

[3] E. Ahmad, M. I. Alam, K. K. Pant, and M. A. Haider, "Catalytic and mechanistic insights into the production of ethyl levulinate from biorenewable feedstocks," Green Chemistry, vol. 18, no. 18, pp. 4804-4823, 2016.
[4] V. M. Chernyshev, O. A. Kravchenko, and V. P. Ananikov, "Conversion of plant biomass to furan derivatives and sustainable access to the new generation of polymers, functional materials and fuels," Russian Chemical Reviews, vol. 86, no. 5, pp. 357-387, 2017.

[5] H. Pan, H. Li, H. Zhang, A. Wang, and S. Yang, "Functional nanomaterials-catalyzed production of biodiesel," Current Nanoscience, vol. 16, no. 3, pp. 376-391, 2020.

[6] H. Li, A. Riisager, S. Saravanamurugan et al., "Carbon-increasing catalytic strategies for upgrading biomass into energy-intensive fuels and chemicals," ACS Catalysis, vol. 8, no. 1, pp. 148-187, 2017.

[7] J. Tan, Y. Li, X. Tan, H. Wu, H. Li, and S. Yang, "Advances in Pretreatment of straw biomass for sugar production," Frontiers in Chemistry, vol. 9, Article ID 696030, 2021.

[8] T. Werpy, G. Petersen, A. Aden, J. J. Bozell, and S. Jones, National Renewable Energy Lab.(NREL), Golden, CO USA, 2004.

[9] M. J. Taherzadeh and K. Karimi, "Acid-based hydrolysis processes for ethanol from lignocellulosic materials: a review," BioResources, vol. 2, no. 3, pp. 472-499, 2007.

[10] Y. Yang, C.-W. Hu, and M. M. Abu-Omar, "Conversion of carbohydrates and lignocellulosic biomass into 5-hydroxymethylfurfural using $\mathrm{AlCl} 3 \cdot 6 \mathrm{H} 2 \mathrm{O}$ catalyst in a biphasic solvent system," Green Chemistry, vol. 14, no. 2, pp. 509-513, 2012.

[11] F. Yang, J. Tang, R. Ou et al., "Fully catalytic upgrading synthesis of 5-ethoxymethylfurfural from biomass-derived 5-hydroxymethylfurfural over recyclable layered-niobiummolybdate solid acid," Applied Catalysis B: Environmental, vol. 256, Article ID 117786, 2019.

[12] D. W. Rackemann and W. O. Doherty, "The conversion of lignocellulosics to levulinic acid," Biofuels, Bioproducts and Biorefining, vol. 5, no. 2, pp. 198-214, 2011.

[13] M. J. Climent, A. Corma, and S. Iborra, "Conversion of biomass platform molecules into fuel additives and liquid hydrocarbon fuels," Green Chemistry, vol. 16, no. 2, p. 516, 2014.

[14] D. M. Alonso, J. Q. Bond, and J. A. Dumesic, "Catalytic conversion of biomass to biofuels," Green Chemistry, vol. 12, no. 9, p. 1493, 2010.

[15] F. Cebreiros, M. D. Ferrari, and C. Lareo, "Cellulose hydrolysis and IBE fermentation of eucalyptus sawdust for enhanced biobutanol production by Clostridium beijerinckii DSM 6423," Industrial Crops and Products, vol. 134, pp. 50-61, 2019.

[16] P. Zhu, O. Y. Abdelaziz, C. P. Hulteberg, and A. Riisager, "New synthetic approaches to biofuels from lignocellulosic biomass," Current Opinion in Green and Sustainable Chemistry, vol. 21, pp. 16-21, 2020.

[17] H. Li, S. Yang, A. Riisager et al., "Zeolite and zeotype-catalysed transformations of biofuranic compounds," Green Chemistry, vol. 18, no. 21, pp. 5701-5735, 2016.

[18] A. Corma, S. Iborra, and A. Velty, "Chemical routes for the transformation of biomass into chemicals," Chemical Reviews, vol. 107, no. 6, pp. 2411-2502, 2007.

[19] H. Liu, X. Tang, W. Hao et al., "One-pot tandem conversion of fructose into biofuel components with in-situ generated catalyst system," Journal of Energy Chemistry, vol. 27, no. 2, pp. 375-380, 2018.

[20] J. Yanowitz, M. A. Ratcliff, R. L. McCormick, J. D. Taylor, and M. J. Murphy, National Renewable Energy Lab.(NREL), Golden, CO, USA, 2017. 
[21] M. Balakrishnan, E. R. Sacia, and A. T. Bell, "Etherification and reductive etherification of 5-(hydroxymethyl)furfural: 5(alkoxymethyl)furfurals and 2,5-bis(alkoxymethyl)furans as potential bio-diesel candidates," Green Chemistry, vol. 14, no. 6, p. 1626, 2012.

[22] E.-J. Ras, B. McKay, and G. Rothenberg, "Understanding catalytic biomass conversion through data mining," Topics in Catalysis, vol. 53, no. 15-18, pp. 1202-1208, 2010.

[23] E.-J. Ras, S. Maisuls, P. Haesakkers, G.-J. Gruter, and G. Rothenberg, "Selective hydrogenation of 5-ethoxymethylfurfural over alumina-supported heterogeneous catalysts," Advanced Synthesis \& Catalysis, vol. 351, no. 18, pp. 3175-3185, 2009.

[24] A. Bredihhin, L. Vares, and S. Luiga, "Application of 5ethoxymethylfurfural (EMF) for the production of cyclopentenones," Synthesis, vol. 48, no. 23, pp. 4181-4188, 2016.

[25] S. Wang, Y. Chen, Y. Jia et al., "Experimental and theoretical studies on glucose conversion in ethanol solution to 5ethoxymethylfurfural and ethyl levulinate catalyzed by a Bronsted acid," Physical Chemistry Chemical Physics, vol. 23, no. 35, pp. 19729-19739, 2021.

[26] B. Vanderhaegen, H. Neven, S. Coghe, K. J. Verstrepen, H. Verachtert, and G. Derdelinckx, "Evolution of chemical and sensory properties during aging of top-fermented beer," Journal of Agricultural and Food Chemistry, vol. 51, no. 23, pp. 6782-6790, 2003.

[27] S. Karnjanakom, P. Phanthong, A. Bayu et al., "Facile in situ 5 -EMF synthesis and extraction processes from catalytic conversion of sugar under sustainable long-life cycle," ACS Sustainable Chemistry \& Engineering, vol. 8, no. 39, pp. 14867-14876, 2020.

[28] Y. Chen, L. Peng, J. Zhang, and L. He, "Synergy of $\mathrm{Al} 2(\mathrm{SO} 4) 3$ and H3PO4 in co-solvents converts starch to 5-ethoxymethylfurfural," Catalysis Communications, vol. 137, Article ID 105947, 2020.

[29] Z. Zhang, Y. Wang, Z. Fang, and B. Liu, "Synthesis of 5ethoxymethylfurfural from fructose and inulin catalyzed by a magnetically recoverable acid catalyst," ChemPlusChem, vol. 79, no. 2, pp. 233-240, 2014.

[30] S. Alipour, H. Omidvarborna, and D.-S. Kim, "A review on synthesis of alkoxymethyl furfural, a biofuel candidate," Renewable and Sustainable Energy Reviews, vol. 71, pp. 908-926, 2017.

[31] A. Liu, B. Liu, Y. Wang, R. Ren, and Z. Zhang, "Efficient onepot synthesis of 5-ethoxymethylfurfural from fructose catalyzed by heteropolyacid supported on K-10 clay," Fuel, vol. 117, pp. 68-73, 2014.

[32] T. Flannelly, S. Dooley, and J. J. Leahy, "Reaction pathway analysis of ethyl levulinate and 5-ethoxymethylfurfural from d-fructose acid hydrolysis in ethanol," Energy \& Fuels, vol. 29, no. 11, pp. 7554-7565, 2015.

[33] H. Li, C. Wang, Y. Xu et al., "Heterogeneous (de)chlorination-enabled control of reactivity in the liquid-phase synthesis of furanic biofuel from cellulosic feedstock," Green Chemistry, vol. 22, no. 3, pp. 637-645, 2020.

[34] M. Mascal and E. B. Nikitin, "Direct, high-yield conversion of cellulose into biofuel," Angewandte Chemie, vol. 120, no. 41, pp. 8042-8044, 2008.

[35] I. Viil, A. Bredihhin, U. Mäeorg, and L. Vares, "Preparation of potential biofuel 5-ethoxymethylfurfural and other 5alkoxymethylfurfurals in the presence of oil shale ash," RSC Advances, vol. 4, no. 11, pp. 5689-5693, 2014.

[36] H. Li, Z. Fang, R. L. Smith, and S. Yang, "Efficient valorization of biomass to biofuels with bifunctional solid catalytic materials," Progress in Energy and Combustion Science, vol. 55, pp. 98-194, 2016.

[37] R.-J. van Putten, J. C. van der Waal, E. de Jong, C. B. Rasrendra, H. J. Heeres, and J. G. de Vries, "Hydroxymethylfurfural, a versatile platform chemical made from renewable resources," Chemical Reviews, vol. 113, no. 3, pp. 1499-1597, 2013.

[38] B. Chen, G. Xu, Z. Zheng, D. Wang, C. Zou, and C. Chang, "Efficient conversion of corn stover into 5-ethoxymethylfurfural catalyzed by zeolite USY in ethanol/THF medium," Industrial Crops and Products, vol. 129, pp. 503511, 2019.

[39] M. Rezaie, M. Dinari, A. N. Chermahini, M. Saraji, and A. Shahvar, "Preparation of kapa carrageenan-based acidic heterogeneous catalyst for conversion of sugars to high-value added materials," International Journal of Biological Macromolecules, vol. 165, pp. 1129-1138, 2020.

[40] H. Guo, X. Qi, Y. Hiraga, T. M. Aida, and R. L. Smith, "Efficient conversion of fructose into 5-ethoxymethylfurfural with hydrogen sulfate ionic liquids as co-solvent and catalyst," Chemical Engineering Journal, vol. 314, pp. 508-514, 2017.

[41] Z. Miao, A. Wj, A. Yf et al., "Effective selectivity conversion of glucose to furan chemicals in the aqueous deep eutectic solvent," Renewable Energy, vol. 164, pp. 23-33, 2021.

[42] Abhinav, R. Kumar, and Srivastava, "FeVO4 decorated - $\mathrm{SO} 3 \mathrm{H}$ functionalized polyaniline for direct conversion of sucrose to 2,5-diformylfuran \& 5-ethoxymethylfurfural and selective oxidation reaction," Molecular Catalysis, vol. 465, pp. 68-79, 2019.

[43] H. Guo, A. Duereh, Y. Hiraga, T. M. Aida, X. Qi, and R. L. Smith, "Perfect recycle and mechanistic role of hydrogen sulfate ionic liquids as additive in ethanol for efficient conversion of carbohydrates into 5-ethoxymethylfurfural," Chemical Engineering Journal, vol. 323, pp. 287-294, 2017.

[44] H. Wang, T. Deng, Y. Wang et al., "Graphene oxide as a facile acid catalyst for the one-pot conversion of carbohydrates into 5-ethoxymethylfurfural," Green Chemistry, vol. 15, no. 9, pp. 2379-2383, 2013

[45] B. Chen, G. Xu, C. Chang et al., "Efficient one-pot production of biofuel 5-ethoxymethylfurfural from corn stover: optimization and kinetics," Energy \& Fuels, vol. 33, no. 5, pp. 4310-4321, 2019.

[46] J. Tan, Q. Liu, L. Chen, T. Wang, L. Ma, and G. Chen, "Efficient production of ethyl levulinate from cassava over $\mathrm{Al}$ 2 (SO 4 ) 3 catalyst in ethanol-water system," Journal of Energy Chemistry, vol. 26, no. 1, pp. 115-120, 2017.

[47] B. Liu, Z. Zhang, K. Huang, and Z. Fang, "Efficient conversion of carbohydrates into 5-ethoxymethylfurfural in ethanol catalyzed by AlCl3," Fuel, vol. 113, pp. 625-631, 2013.

[48] H. Xin, T. Zhang, W. Li et al., "Dehydration of glucose to 5hydroxymethylfurfural and 5-ethoxymethylfurfural by combining Lewis and Brønsted acid," RSC Advances, vol. 7, no. 66, pp. 41546-41551, 2017.

[49] J. Li, Y. Wang, B. Lu, Y. Wang, T. Deng, and X. Hou, "Protonic acid catalysis of sulfonated carbon material: tunable and selective conversion of fructose in low-boiling point solvent," Applied Catalysis A: General, vol. 566, pp. 140-145, 2018.

[50] Y. Chen, W. Guan, Y. Zhang et al., "One-pot synthesis of the biofuel 5-ethoxymethylfurfural from carbohydrates using a bifunctional catalyst prepared through a pickering HIPE 
template and pore-filled strategy," Energy \& Fuels, vol. 34, no. 11, pp. 14264-14274, 2020.

[51] L. Zhang, Y. Zhu, L. Tian, Y. He, H. Wang, and F. Deng, "One-pot alcoholysis of carbohydrates to biofuel 5-ethoxymethylfufural and 5-methoxymethylfufural via a sulfonic porous polymer," Fuel Processing Technology, vol. 193, pp. 39-47, 2019.

[52] G. Xu, B. Chen, Z. Zheng, K. Li, and H. Tao, "One-pot ethanolysis of carbohydrates to promising biofuels: 5ethoxymethylfurfural and ethyl levulinate," Asia-Pacific Journal of Chemical Engineering, vol. 12, no. 4, pp. 527-535, 2017.

[53] S. Dutta, S. De, M. I. Alam, M. M. Abu-Omar, and B. Saha, "Direct conversion of cellulose and lignocellulosic biomass into chemicals and biofuel with metal chloride catalysts," Journal of Catalysis, vol. 288, pp. 8-15, 2012.

[54] S. Yin, J. Sun, B. Liu, and Z. Zhang, "Magnetic material grafted cross-linked imidazolium based polyionic liquids: an efficient acid catalyst for the synthesis of promising liquid fuel 5-ethoxymethylfurfural from carbohydrates," Journal of Materials Chemistry A, vol. 3, no. 9, pp. 4992-4999, 2015.

[55] Y. Yang, M. M. Abu-Omar, and C. Hu, "Heteropolyacid catalyzed conversion of fructose, sucrose, and inulin to 5ethoxymethylfurfural, a liquid biofuel candidate," Applied Energy, vol. 99, pp. 80-84, 2012.

[56] B. Liu and Z. Zhang, "One-pot conversion of carbohydrates into 5-ethoxymethylfurfural and ethyl D-glucopyranoside in ethanol catalyzed by a silica supported sulfonic acid catalyst," RSC Advances, vol. 3, no. 30, p. 12313, 2013.

[57] H. Hafizi, G. Walker, J. Iqbal, J. J. Leahy, and M. N. Collins, "Catalytic etherification of 5-hydroxymethylfurfural into 5ethoxymethyfurfural over sulfated bimetallic SO42-/Al-Zr/ KIT-6, a Lewis/Brønsted acid hybrid catalyst," Molecular Catalysis, vol. 496, Article ID 111176, 2020.

[58] Y. Bai, L. Wei, M. Yang et al., "Three-step cascade over a single catalyst: synthesis of 5-(ethoxymethyl)furfural from glucose over a hierarchical lamellar multi-functional zeolite catalyst," Journal of Materials Chemistry A, vol. 6, no. 17, pp. 7693-7705, 2018.

[59] L. Bing, Z. Zhang, and K. Deng, "Efficient one-pot synthesis of 5-(ethoxymethyl)furfural from fructose catalyzed by a novel solid catalyst," Industrial \& Engineering Chemistry Research, vol. 51, no. 47, pp. 15331-15336, 2012.

[60] X. Zhou, Z. Zhang, B. Liu, Q. Zhou, S. Wang, and K. Deng, "Catalytic conversion of fructose into furans using $\mathrm{FeCl} 3$ as catalyst," Journal of Industrial and Engineering Chemistry, vol. 20, no. 2, pp. 644-649, 2014.

[61] Y. Yang, C. Hu, and M. M. Abu-Omar, "Conversion of glucose into furans in the presence of $\mathrm{AlCl} 3$ in an ethanolwater solvent system," Bioresource Technology, vol. 116, pp. 190-194, 2012.

[62] J. Liu, Y. Tang, K. Wu, C. Bi, and Q. Cui, "Conversion of fructose into 5-hydroxymethylfurfural (HMF) and its derivatives promoted by inorganic salt in alcohol," Carbohydrate Research, vol. 350, pp. 20-24, 2012.

[63] X. Yu, X. Gao, R. Tao, and L. Peng, "Insights into the metal salt catalyzed 5-ethoxymethylfurfural synthesis from carbohydrates," Catalysts, vol. 7, no. 6, p. 182, 2017.

[64] X. Jia, J. Ma, P. Che et al., "Direct conversion of fructosebased carbohydrates to 5-ethoxymethylfurfural catalyzed by $\mathrm{AlCl} 3 \cdot 6 \mathrm{H} 2 \mathrm{O} / \mathrm{BF} 3 \cdot(\mathrm{Et}) 2 \mathrm{O}$ in ethanol," Journal of Energy Chemistry, vol. 22, no. 1, pp. 93-97, 2013.

[65] P. K. Kumari, B. S. Rao, D. Dhana Lakshmi, N. R. Sai Paramesh, C. Sumana, and N. Lingaiah, "Tungstophosphoric acid supported on mesoporouus niobiumoxophosphate: an efficient solid acid catalyst for etherification of 5-hydroxymethylfurfural to 5-ethoxymethylfurfural," Catalysis Today, vol. 325, pp. 53-60, 2019.

[66] G. Morales, M. Paniagua, J. A. Melero, and J. Iglesias, "Efficient production of 5-ethoxymethylfurfural from fructose by sulfonic mesostructured silica using DMSO as co-solvent," Catalysis Today, vol. 279, pp. 305-316, 2017.

[67] J. Dai, Z. Liu, Y. Hu et al., "Adjusting the acidity of sulfonated organocatalyst for the one-pot production of 5-ethoxymethylfurfural from fructose," Catalysis Science \& Technology, vol. 9, no. 2, pp. 483-492, 2019.

[68] K. Zhao, S. Liu, K. Li et al., "Fabrication of $-\mathrm{SO} 3 \mathrm{H}$ functionalized aromatic carbon microspheres directly from waste Camellia oleifera shells and their application on heterogeneous acid catalysis," Molecular Catalysis, vol. 433, pp. 193-201, 2017.

[69] Z. Zhang and G. W. Huber, "Catalytic oxidation of carbohydrates into organic acids and furan chemicals," Chemical Society Reviews, vol. 47, no. 4, pp. 1351-1390, 2018.

[70] A. Liu, Z. Zhang, Z. Fang, B. Liu, and K. Huang, "Synthesis of 5-ethoxymethylfurfural from 5-hydroxymethylfurfural and fructose in ethanol catalyzed by MCM-41 supported phosphotungstic acid," Journal of Industrial and Engineering Chemistry, vol. 20, no. 4, pp. 1977-1984, 2014.

[71] P. Che, F. Lu, J. Zhang et al., "Catalytic selective etherification of hydroxyl groups in 5-hydroxymethylfurfural over H4SiW12O40/MCM-41 nanospheres for liquid fuel production," Bioresource Technology, vol. 119, pp. 433-436, 2012.

[72] G. Xu, S. Zhang, Z. Zheng, C. Wang, S. Wang, and H. Tao, "Direct conversion of fructose to 5-ethoxymethyl-furfural catalyzed by ultra stable Y zeolite," BioResources, vol. 15, no. 2, pp. 3621-3635, 2020.

[73] S. Wang, Z. Zhang, B. Liu, and J. Li, "Silica coated magnetic $\mathrm{Fe} 3 \mathrm{O} 4$ nanoparticles supported phosphotungstic acid: a novel environmentally friendly catalyst for the synthesis of 5ethoxymethylfurfural from 5-hydroxymethylfurfural and fructose," Catalysis Science \& Technology, vol. 3, no. 8, pp. 2104-2112, 2013.

[74] Z. Wang, H. Li, C. Fang, W. Zhao, T. Yang, and S. Yang, "Simply assembly of acidic nanospheres for efficient production of 5-ethoxymethylfurfural from 5-hydromethylfurfural and fructose," Energy Technology, vol. 5, no. 11, pp. 2046-2054, 2017.

[75] J. Wang, Z. Zhang, S. Jin, and X. Shen, "Efficient conversion of carbohydrates into 5-hydroxylmethylfurfan and 5ethoxymethylfurfural over sufonic acid-functionalized mesoporous carbon catalyst," Fuel, vol. 192, pp. 102-107, 2017.

[76] C. Wang, K. Li, and P. Ji, "Using taurine to increase mesopores in Ce -based metal-organic framework for enhancing the production of 5-hydroxymethylfurfural and 5-ethoxymethylfurfural from fructose," Journal of Chemical Technology and Biotechnology, vol. 96, no. 1, pp. 163-171, 2020.

[77] L. Zhang, L. Tian, G. Xi, R. Sun, and X. Zhao, "Catalytic valorization of expired fructan-rich food into the biofuel 5ethoxymethylfurfural via a restaurant food waste-derived carbonaceous solid acid," Waste and Biomass Valorization, vol. 11, no. 11, pp. 6223-6233, 2019.

[78] Y. Xiang, S. Wen, Y. Tian et al., "Efficient synthesis of 5ethoxymethylfurfural from biomass-derived 5-hydroxymethylfurfural over sulfonated organic polymer catalyst," RSC Advances, vol. 11, no. 6, pp. 3585-3595, 2021. 
[79] T. Chen, L. Peng, X. Yu, and L. He, "Magnetically recyclable cellulose-derived carbonaceous solid acid catalyzed the biofuel 5-ethoxymethylfurfural synthesis from renewable carbohydrates," Fuel, vol. 219, pp. 344-352, 2018.

[80] H. Li, S. Saravanamurugan, S. Yang, and A. Riisager, "Direct transformation of carbohydrates to the biofuel 5-ethoxymethylfurfural by solid acid catalysts," Green Chemistry, vol. 18, no. 3, pp. 726-734, 2016.

[81] P. Lanzafame, D. M. Temi, S. Perathoner et al., "Etherification of 5-hydroxymethyl-2-furfural (HMF) with ethanol to biodiesel components using mesoporous solid acidic catalysts," Catalysis Today, vol. 175, no. 1, pp. 435-441, 2011.

[82] M. N. Timofeeva, "Acid catalysis by heteropoly acids," Applied Catalysis A: General, vol. 256, no. 1-2, pp. 19-35, 2003.

[83] I. V. Kozhevnikov, "Catalysis by heteropoly acids and multicomponent polyoxometalates in liquid-phase reactions," Chemical Reviews, vol. 98, no. 1, pp. 171-198, 1998.

[84] G. M. Whitesides and B. Grzybowski, "Self-assembly at all scales," Science, vol. 295, no. 5564, pp. 2418-2421, 2002.

[85] N. García-Bosch, B. Bachiller-Baeza, I. Rodríguez-Ramos, and A. Guerrero-Ruiz, "Fructose transformations in ethanol using carbon supported polyoxometalate acidic solids for 5ethoxymethylfurfural production," ChemCatChem, vol. 10, no. 17, pp. 3746-3753, 2018.

[86] H. Li, Q. Zhang, and S. Yang, "Catalytic cascade dehydration-etherification of fructose into 5-ethoxymethylfurfural with $\mathrm{SO} 3 \mathrm{H}$-functionalized polymers," International Journal of Chemical Engineering, vol. 2014, Article ID 481627, 7 pages, 2014.

[87] X. Liu, H. Li, H. Pan et al., "Efficient catalytic conversion of carbohydrates into 5-ethoxymethylfurfural over MIL-101based sulfated porous coordination polymers," Journal of Energy Chemistry, vol. 25, no. 3, pp. 523-530, 2016.

[88] M. M. Antunes, P. A. Russo, P. V. Wiper et al., "Sulfonated graphene oxide as effective catalyst for conversion of 5(hydroxymethyl)-2-furfural into biofuels," ChemSusChem, vol. 7, no. 3, pp. 804-812, 2014.

[89] Z. Wang and Q. Chen, "Variations of major product derived from conversion of 5-hydroxymethylfurfural over a modified MOFs-derived carbon material in response to reaction conditions," Nanomaterials, vol. 8, no. 7, p. 492, 2018.

[90] Y. Wen, Z. Yu, K. Li, H. Guo, Y. Dai, and L. Yan, "Fabrication of biobased heterogeneous solid Brønsted acid catalysts and their application on the synthesis of liquid biofuel 5ethoxymethylfurfural from fructose," Green Energy \& Environment, vol. 3, no. 4, pp. 384-391, 2018.

[91] X. Yu, L. Peng, X. Gao, L. He, and K. Chen, "One-step fabrication of carbonaceous solid acid derived from lignosulfonate for the synthesis of biobased furan derivatives," RSC Advances, vol. 8, no. 28, pp. 15762-15772, 2018.

[92] R. S. Thombal and V. H. Jadhav, "Application of glucose derived magnetic solid acid for etherification of 5-HMF to 5EMF, dehydration of sorbitol to isosorbide, and esterification of fatty acids," Tetrahedron Letters, vol. 57, no. 39, pp. 4398-4400, 2016.

[93] B. Liu, Z. Zhang, and K. Huang, "Cellulose sulfuric acid as a bio-supported and recyclable solid acid catalyst for the synthesis of 5-hydroxymethylfurfural and 5-ethoxymethylfurfural from fructose," Cellulose, vol. 20, no. 4, pp. 2081-2089, 2013.

[94] Z. Yuan, Z. Zhang, J. Zheng, and J. Lin, "Efficient synthesis of promising liquid fuels 5-ethoxymethylfurfural from carbohydrates," Fuel, vol. 150, pp. 236-242, 2015.
[95] Y.-Y. Bai, S. Su, S. Wang et al., "Catalytic conversion of carbohydrates into 5-ethoxymethylfurfural by a magnetic solid acid using $\gamma$-valerolactone as a Co-solvent," Energy Technology, vol. 6, no. 10, pp. 1951-1958, 2018.

[96] H. Guo, A. Duereh, Y. Hiraga, X. Qi, and R. L. Smith, "Mechanism of glucose conversion into 5-ethoxymethylfurfural in ethanol with hydrogen sulfate ionic liquid additives and a Lewis acid catalyst," Energy \& Fuels, vol. 32, no. 8, pp. 8411-8419, 2018.

[97] M. I. Alam, S. De, T. S. Khan, M. A. Haider, and B. Saha, "Acid functionalized ionic liquid catalyzed transformation of non-food biomass into platform chemical and fuel additive," Industrial Crops and Products, vol. 123, pp. 629-637, 2018.

[98] B. Srinivasa Rao, D. Dhana Lakshmi, P. Krishna Kumari, P. Rajitha, and N. Lingaiah, "Dehydrative etherification of carbohydrates to 5-ethoxymethylfurfural over SBA-15-supported Sn-modified heteropolysilicate catalysts," Sustainable Energy \& Fuels, vol. 4, no. 7, pp. 3428-3437, 2020.

[99] S. Karnjanakom and P. Maneechakr, "Designs of linearquadratic regression models for facile conversion of carbohydrate into high value (5-(ethoxymethyl)furan-2-carboxaldehyde) fuel chemical," Energy Conversion and Management, vol. 196, pp. 410-417, 2019.

[100] A. B. Gawade and G. D. Yadav, "Microwave assisted synthesis of 5-ethoxymethylfurfural in one pot from d-fructose by using deep eutectic solvent as catalyst under mild condition," Biomass and Bioenergy, vol. 117, pp. 38-43, 2018.

[101] M. Zuo, K. Le, Y. Feng et al., "An effective pathway for converting carbohydrates to biofuel 5-ethoxymethylfurfural via 5hydroxymethylfurfural with deep eutectic solvents (DESs)," Industrial Crops and Products, vol. 112, pp. 18-23, 2018.

[102] D. Zhao, M. Wu, Y. Kou, and E. Min, "Ionic liquids: applications in catalysis," Catalysis Today, vol. 74, no. 1-2, pp. 157-189, 2002.

[103] V. I. Pârvulescu and C. Hardacre, "Catalysis in ionic liquids," Chemical Reviews, vol. 107, no. 6, pp. 2615-2665, 2007.

[104] T. Welton, "Ionic liquids in catalysis," Coordination Chemistry Reviews, vol. 248, no. 21-24, pp. 2459-2477, 2004.

[105] S. Xin, Q. Wang, J. Xu et al., "The acidic nature of "NMR-invisible" tri-coordinated framework aluminum species in zeolites," Chemical Science, vol. 10, no. 43, pp. 10159-10169, 2019.

[106] Q. Zhang, K. De Oliveira Vigier, S. Royer, and F. Jérôme, "Deep eutectic solvents: syntheses, properties and applications," Chemical Society Reviews, vol. 41, no. 21, pp. 7108-7146, 2012.

[107] J. T. Gorke, F. Srienc, and R. J. Kazlauskas, "Hydrolase-catalyzed biotransformations in deep eutectic solvents," Chemical Communications, vol. 10, no. 10, pp. 1235-1237, 2008.

[108] E. L. Smith, A. P. Abbott, and K. S. Ryder, "Deep eutectic solvents (DESs) and their applications," Chemical Reviews, vol. 114, no. 21, pp. 11060-11082, 2014.

[109] F. Ilgen, D. Ott, D. Kralisch, C. Reil, A. Palmberger, and B. König, "Conversion of carbohydrates into 5-hydroxymethylfurfural in highly concentrated low melting mixtures," Green Chemistry, vol. 11, no. 12, p. 1948, 2009.

[110] M. Zuo, K. Le, Z. Li et al., "Green process for production of 5hydroxymethylfurfural from carbohydrates with high purity in deep eutectic solvents," Industrial Crops and Products, vol. 99, pp. 1-6, 2017.

[111] J. Zhang, K. Dong, W. Luo, and H. Guan, "Catalytic upgrading of carbohydrates into 5-ethoxymethylfurfural using $\mathrm{SO} 3 \mathrm{H}$ functionalized hyper-cross-linked polymer based carbonaceous materials," Fuel, vol. 234, pp. 664-673, 2018. 